\title{
Position Control of a Pneumatic Muscle Actuator Using RBF Neural Network Tuned PID Controller
}

\author{
Jie Zhao, Jun Zhong, and Jizhuang Fan \\ State Key Laboratory of Robotics and System, Harbin Institute of Technology, Harbin 150001, China \\ Correspondence should be addressed to Jizhuang Fan; fanjizhuang@hit.edu.cn
}

Received 1 September 2014; Revised 19 March 2015; Accepted 19 March 2015

Academic Editor: Seungik Baek

Copyright (C) 2015 Jie Zhao et al. This is an open access article distributed under the Creative Commons Attribution License, which permits unrestricted use, distribution, and reproduction in any medium, provided the original work is properly cited.

Pneumatic Muscle Actuator (PMA) has a broad application prospect in soft robotics. However, PMA has highly nonlinear and hysteretic properties among force, displacement, and pressure, which lead to difficulty in accurate position control. A phenomenological model is developed to portray the hysteretic behavior of PMA. This phenomenological model consists of linear component and hysteretic component force. The latter component is described by Duhem model. An experimental apparatus is built up and sets of experimental data are acquired. Based on the experimental data, parameters of the model are identified. Validation of the model is performed. Then a novel cascade position PID controller is devised for a 1-DOF manipulator actuated by PMA. The outer loop of the controller is to cope with position control whilst the inner loop deals with pressure dynamics within PMA. To enhance the adaptability of the PID algorithm to the high nonlinearities of the manipulator, PID parameters are tuned online using RBF Neural Network. Experiments are performed and comparison between position response of RBF Neural Network based PID controller and that of classic PID controller demonstrates the effectiveness of the novel adaptive controller on the manipulator.

\section{Introduction}

Pneumatic Muscle Actuator (PMA) has been widely applied for soft robotics, flexible surgical tools, and prosthetic applications because of its similarity in compliance with natural muscle [1-7]. PMA is not complicated in construction. It mainly includes two components: a flexible inner cylindrical containment layer and an outer cylindrical braided woven layer with end caps to seal the cylinders. The braided layer is made of nylon threads of high stiffness. These threads are placed in double helix form in outer surface or mixed with inner bladder. The inner tube, made of latex material or silicone, exhibits the capacity of large deformation. When the inner rubber bladder is pressurized, it produces elastic deformation and imposes elastic forces on the outer braided mesh; due to strong stiffness of nylon lines, the fiber layer drives latex rubber to inflate in radial direction and shorten in axial direction [8-12].

1.1. Review of Modeling PMA. Despite attractive advantages, PMA has high nonlinear properties and hysteretic characteristics which are produced by air complexity and nonlinearity of its own geometric construction. To describe its nonlinear properties, many researchers have proposed various static and/or dynamic mathematical models [13-20]. Schulte proposed the earliest static model to describe the relationship among output force of PMA, supplied pressure, and contractile displacement [19]. Subsequently, Chou developed his static model based on principle of virtual work [13]. In his model, finite thickness of the containment layers and strandon-strand friction were considered. Tsagarakis and Caldwell used force balancing equations to study the static properties of PMA and similar model with Chou was derived [21]. Stretch of the braid fiber during contracting process was considered by researchers [22]. The elasticity of the bladder has been considered to be an important factor influencing PMA $[23,24]$. Friction within PMA causes hysteresis in increasing and decreasing contraction and was considered in some theoretical models $[13,25]$. Another approach is modeling from phenomenological behaviors of PMA. Minh et al. [26] developed an attractive static model based on Maxwell-slip model; Wickramatunge and Leephakpreeda [27] regarded the PMA as a mechanical spring with variable stiffness and initial length at different pressures within PMA. 
In this paper a new phenomenological model is proposed to portray the hysteresis and nonlinearity among actuating force, contractile displacement, and pressurized pressure using Duhem model. Compared with Maxwell-slip model in [26] and polynomial equation in [27], Duhem model is easier to be calculated and programmed in $\mathrm{C}++$ language, which is important in real-time control.

1.2. Review of Controlling PMA. Owing to the high nonlinearities and hysteresis inside PMA, it is not easy to implement position control accurately. Many attempts have been made to improve the control algorithm for PMA. Caldwell et al. proposed adaptive pole-placement scheme to address the nonlinearity of PMA [28]. Repperger et al. used gain scheduling approach [29], and fuzzy PD+I controller by Chan et al. in [30]. Carbonell et al. [31] developed a robust backstepping controller on the basis of a three-element actuator model. Sliding model $[32,33]$, saturated adaptive robust control [34], and predictive control [35] have been developed for position control. In [36] adaptive fuzzy sliding-mode control was applied to muscle position control and inversion based control concept was used in [37].

Although kinds of advanced controlling techniques have been developed, most adopted control algorithm in industry is still PID controller. To realize position control of PMA in industrial production, improvements of classic PID controller must be made. To better handle the nonlinearity and hysteresis in PMA, a cascade PID based controller is devised. Inner loop of the novel controller is to manipulate the pressure dynamics and the outer loop is to handle position control problem. To enhance the adaptiveness of the controller, RBF Neural Network is used to online tune the parameters of PID controller.

This paper is organized as follows. Section 2 develops the phenomenological model for PMA, Section 3 designs the cascade position controller using RBF Neural Network, and Section 4 designs the 1-DOF manipulator actuated by PMA and gives the experimental validation of the proposed controller.

\section{Phenomenological Model for PMA}

2.1. Introduction of Duhem Model. Duhem model, which was originally developed to describe magnetic hysteresis, has proven suitable for describing piezoelectric hysteresis in [38]. In this research, Duhem model will be adopted to describe the hysteretic component force of contractile force of PMA. As a first-order differential equation, it has a compact form in

$$
\dot{z}=\alpha|\dot{x}|(\beta x-z)+\gamma \dot{x}
$$

where $z$ represents the hysteretic component force in this paper, $x$ is the contractile displacement of PMA, and parameters $\alpha, \beta$, and $\gamma$ characterize the hysteretic loop's magnitude and shape. In order to better describe the hysteretic behavior of PMA, the total contractile force is divided into linear component and hysteretic component in

$$
F=L+z=k x+f_{0}+z .
$$

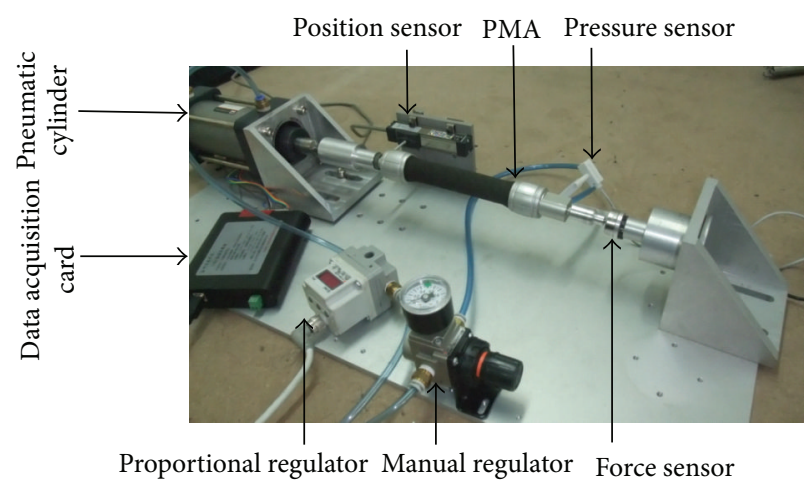

FIgURE 1: Experimental setup for modeling PMA.

When (2) is employed to portray the hysteretic behavior of PMA, five parameters $k, f_{0}, \alpha, \beta$, and $\gamma$ need to be identified. Firstly, parameters $k$ and $f_{0}$ in linear component are optimized by least squares method; then parameters $\alpha, \beta$, and $\gamma$ which control the shape and magnitude of hysteretic loop are identified.

2.2. Design the Setup for Modeling. Experimental apparatus for modeling PMA is shown in Figure 1. A PMA (FESTO Corporation, type of DMSP-20-120RMCM) is characterized in this experiment. This setup consists of three sensors: force sensor, displacement sensor, and pressure sensor. Three types of information about force, displacement, and pressure, are sampled by data acquisition card. Proportional regulator (SMC, type of ITV1050-212N) and manual regulator (SMC, type of AR20-02) are used to tune the amount of air flowed to pneumatic cylinder and PMA, respectively.

2.3. Parameter Identification and Validation of the Phenomenological Model. In parameter identification procedure, predetermined pressure is applied to the muscle first and then triangular waves of pressure with frequency $0.1 \mathrm{~Hz}$ but different magnitudes are applied to pneumatic cylinder. By tuning pressure within the PMA, sets of experimental forces and displacements are sampled, one of which is plotted in Figure 2. Pressure of $0.3102 \mathrm{MPa}$ is applied to PMA. By applying least square curve method, the hysteresis is divided into linear component and hysteretic component, respectively. The parameters of linear component and hysteretic component force are optimized and their values are listed as follows:

$$
\begin{gathered}
k=-30.71, \\
f_{0}=598.4, \\
\alpha=-167.2708, \\
\beta=-0.6946, \\
\gamma=-10646 .
\end{gathered}
$$

Actually, hysteretic loops are different in shape as pressure inside PMA varies. Through the parameter identification procedure and on the basis of different sets of experimental 


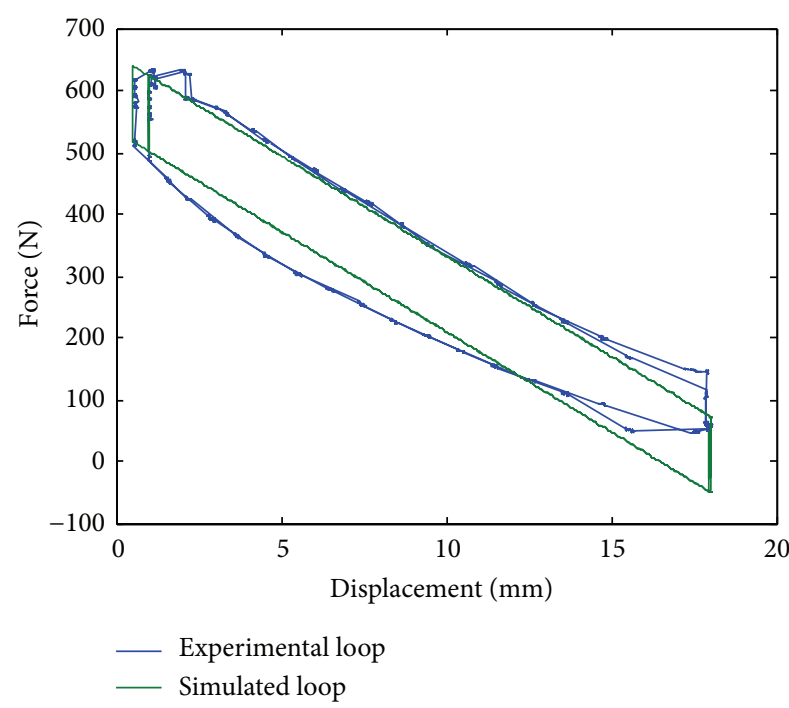

Figure 2: The hysteretic curve of the output displacement versus force with pressure of $0.3102 \mathrm{MPa}$ within PMA.

data, parameters of the proposed model are grouped and fitted into five quadratic polynomial equations with respect to pressure within PMA (Table 1).

To verify the proposed model, validation experiments are conducted. PMA is pressurized to $0.3984 \mathrm{MPa}$. Pressure applied to pneumatic cylinder is shown in Figure 3(a) while the experimental and simulated displacement-force hysteretic curves are plotted in Figure 3(b). Comparison between experimental and simulated curves shows good capacity of the phenomenological model in describing PMA's nonlinearity. Figure 4(a) shows another sinusoidal wave pressure with frequency $0.2 \mathrm{~Hz}$ and magnitude $0.31 \mathrm{MPa}$ applied to pneumatic cylinder when PMA is at pressure of $0.451 \mathrm{MPa}$. Corresponding experimental and simulated hysteretic loops are plotted in Figure 4(b), which further indicates the ability of the model to portray the behavior of PMA.

\section{Cascade Position Controller for PMA}

3.1. Dynamic RBF Neural Network. As a feed-forward neural network, RBF Neural Network (RBFNN) consists of three layers (Figure 5). Considering the actual situation in this paper, these three layers are supposed to have three, four, and one nodes, respectively. Usually, the nonlinear transfer function in hidden node is chosen as Gaussian transfer function. Values of hidden nodes are derived from (4) and the output of the RBFNN is calculated using (5) as follows:

$$
\begin{gathered}
h_{i}=\exp \left\{\frac{1}{2 b_{i}^{2}}\left[\left(x_{1}-C_{i 1}\right)^{2}+\left(x_{2}-C_{i 2}\right)^{2}+\left(x_{3}-C_{i 3}\right)^{2}\right]\right\} \\
y_{m}=w_{1} h_{1}+w_{2} h_{2}+w_{3} h_{3}+w_{4} h_{4}
\end{gathered}
$$

where $X=\left[x_{1}, x_{2}, x_{3}\right]^{T}$ is the input vector of RBFNN, $b_{i}(i=$ $1,2,3,4)$ the base width of the $i$ th node in hidden layer, $C_{i}=$ $\left[C_{i 1}, C_{i 2}, C_{i 3}\right]^{T}$ the center vector of $i$ th node in hidden layer,
TABLE 1: Polynomial equations between parameters of Duhem model and pressure within PMA.

\begin{tabular}{lccc}
\hline Element & \multicolumn{3}{c}{ Element $=a p^{2}+b p+c$} \\
\hline$k$ & $a$ & $b$ & $c$ \\
$f_{0}$ & -59.98 & 18.16 & -30.88 \\
$\alpha$ & -1585 & 3185 & -240.7 \\
$\beta$ & 6215 & -2683 & 379.9 \\
$\gamma$ & 68.36 & -45.24 & 6.068 \\
\hline
\end{tabular}

and $w_{j}(j=1,2,3,4)$ the connection weight of the $j$ th node to the output layer.

Adopting the gradient descent algorithm as the learning algorithm, the instantaneous cost function is defined as

$$
J(k)=\frac{1}{2}\left(y_{m}(k)-y_{\text {out }}(k)\right)^{2},
$$

where $y_{\text {out }}(k)$ is the desired output. If we define $\eta$ as the learning rate and $\alpha$ the inertia factor, then weights of RBFNN, node base widths, and node vector are updated as follows:

$$
\begin{gathered}
w_{j}(k)=w_{j}(k-1)+\eta\left(y_{\text {out }}(k)-y_{m}(k)\right) h_{j} \\
+\alpha\left(w_{j}(k-1)-w_{j}(k-2)\right) \\
\Delta b_{j}=\left(y_{\text {out }}(k)-y_{m}(k)\right) w_{j} h_{j} \frac{\sum_{i=1}^{3}\left(x_{i}-C_{j i}\right)^{2}}{b_{j}^{3}} \\
b_{j}(k)=b_{j}(k-1)+\eta \Delta b_{j}+\alpha\left(b_{j}(k-1)-b_{j}(k-2)\right) \\
\Delta C_{j i}=\left(y_{\text {out }}(k)-y_{m}(k)\right) w_{j} \frac{x_{j}-C_{j i}}{b_{j}^{2}} \\
C_{j i}(k)=C_{j i}(k-1)+\eta \Delta C_{j i}+\alpha\left(C_{j i}(k-1)-C_{j i}(k-2)\right) .
\end{gathered}
$$

3.2. Adaptive PID Controller Based on Dynamic RBFNN. If parameters of digital incremental PID controller are tuned automatically according to actual situation, it could improve the performance of the plant. In this paper, RBFNN is adopted in tuning PID parameters and the principle is shown in Figure 6. The input vector of RBFNN is $[u(k)$, $\left.y_{\text {out }}(k), y_{\text {out }}(k-1)\right]^{T}$. The criteria used in tuning PID parameters are listed as follows:

$$
\begin{gathered}
E(k)=\frac{1}{2}\left[y_{\text {out }}(k)-y_{\text {ref }}(k)\right]^{2}=\frac{1}{2} e^{2}(k) \\
\Delta k_{p}=-\eta \frac{\partial E}{\partial k_{p}}=-\eta \frac{\partial E}{\partial y_{\text {out }}} \frac{\partial y_{\text {out }}}{\partial u} \frac{\partial u}{\partial k_{p}} \\
\Delta k_{i}=-\eta \frac{\partial E}{\partial k_{i}}=-\eta \frac{\partial E}{\partial y_{\text {out }}} \frac{\partial y_{\text {out }}}{\partial u} \frac{\partial u}{\partial k_{i}} \\
\Delta k_{d}=-\eta \frac{\partial E}{\partial k_{d}}=-\eta \frac{\partial E}{\partial y_{\text {out }}} \frac{\partial y_{\text {out }}}{\partial u} \frac{\partial u}{\partial k_{d}}
\end{gathered}
$$




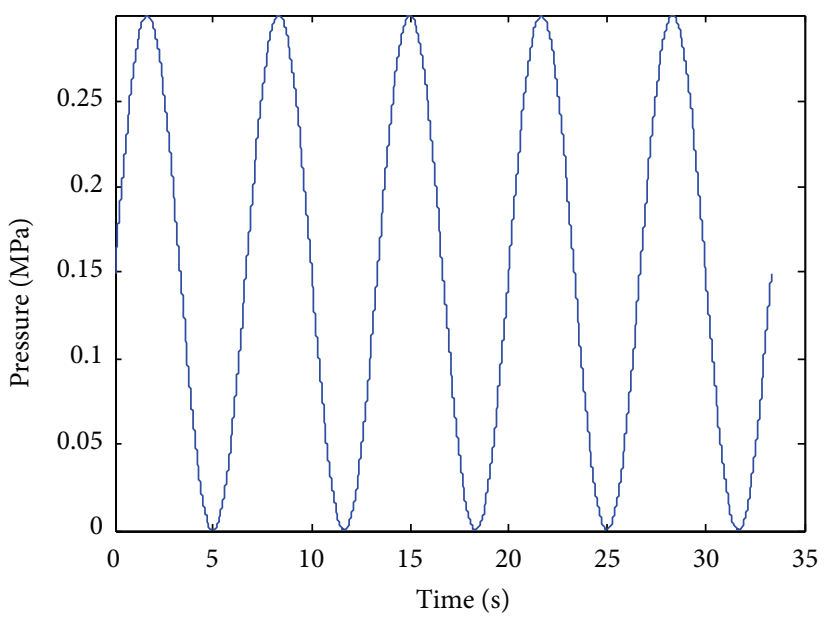

(a)

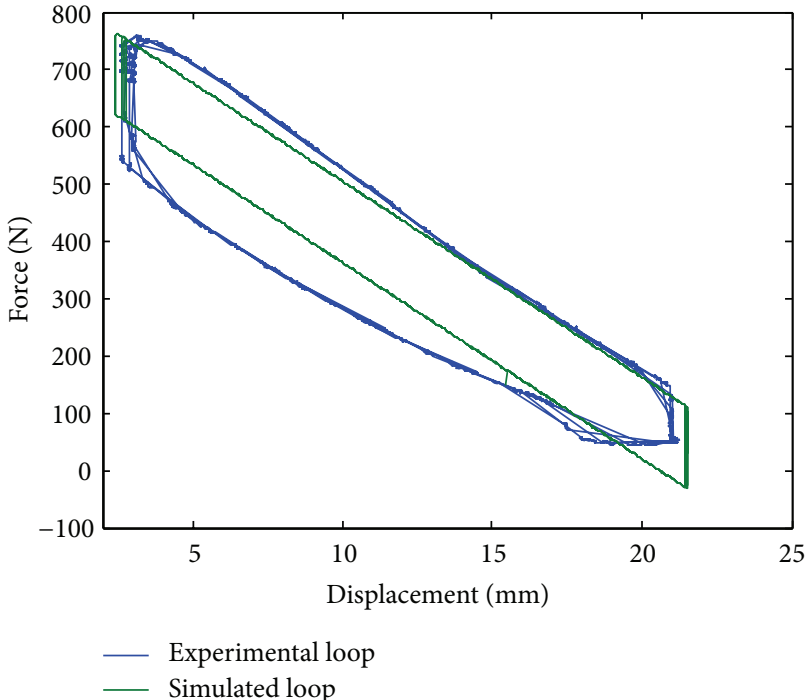

(b)

Figure 3: Time histories of the pressure applied to pneumatic cylinder and the displacement/force hysteretic curves with pressure of 0.3984 MPa in PMA: (a) the pressure applied to pneumatic cylinder and (b) experimental and predicted displacement/force hysteretic curves.

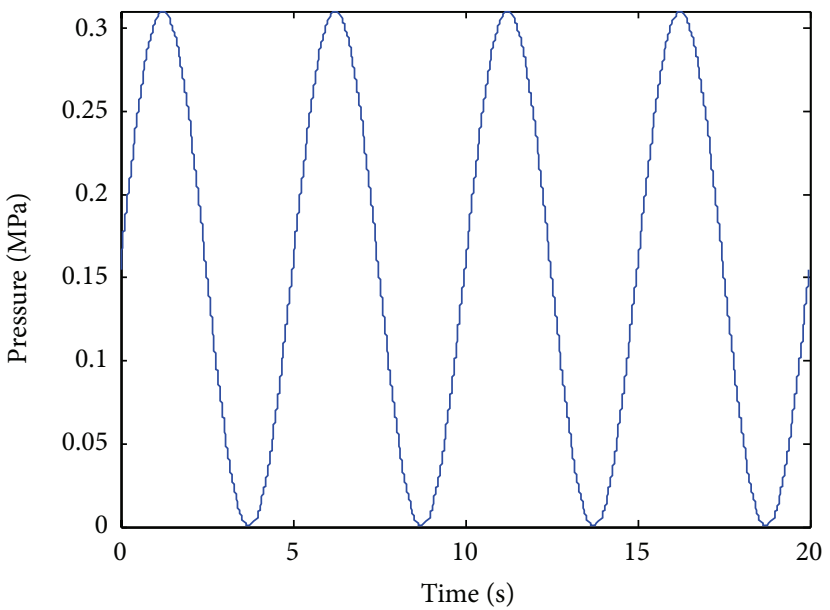

(a)

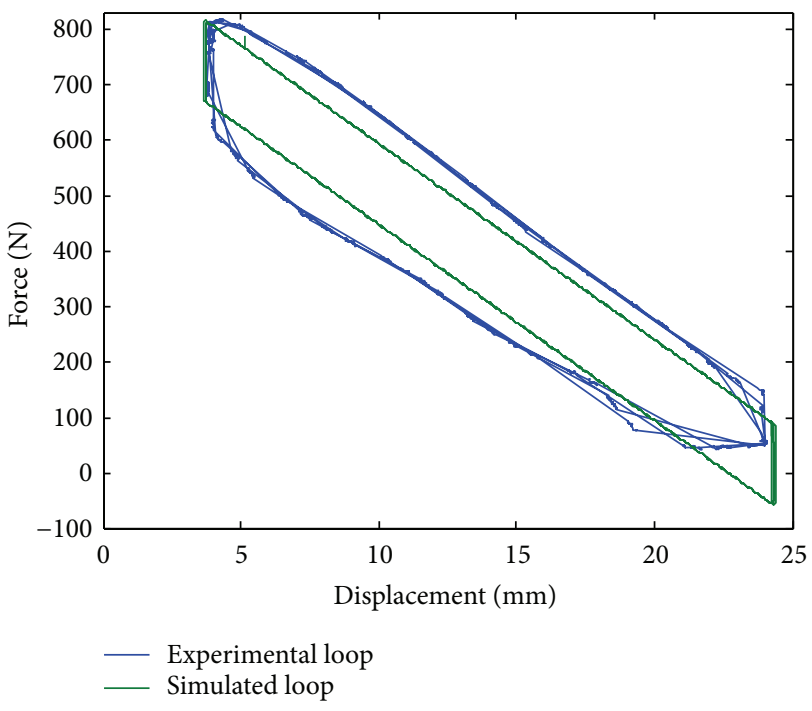

(b)

FIGURE 4: Time histories of the pressure applied to pneumatic cylinder and the displacement/force hysteretic curves with pressure of $0.451 \mathrm{MPa}$ in PMA: (a) the pressure applied to pneumatic cylinder and (b) experimental and predicted displacement/force hysteretic curves.

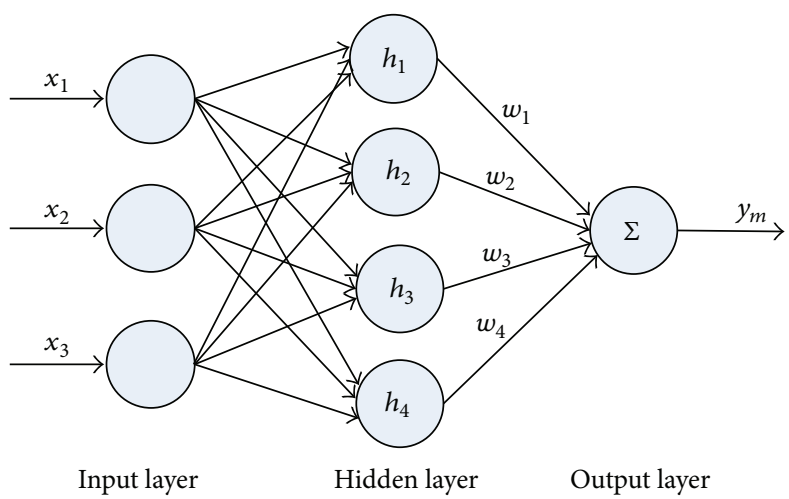

FIgURE 5: Architecture of RBF neural network. 


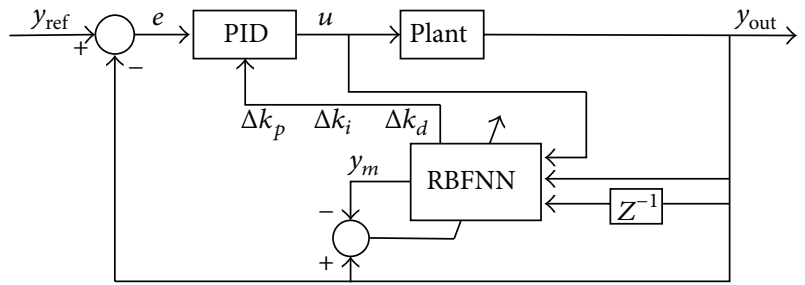

Figure 6: RBFNN tuned PID controller.

$$
\begin{gathered}
k_{p}=k_{p}(0)+\Delta k_{p} \\
k_{d}=k_{d}(0)+\Delta k_{d} \\
k_{i}=k_{i}(0)+\Delta k_{i},
\end{gathered}
$$

where $u(k)$ is output of PID controller and $E(k)$ is the performance function to adjust PID parameters $k_{p}, k_{i}$, and $k_{d}$.

Obviously, using the formulation $\Delta u(k)=k_{p} \Delta e(k)+$ $k_{i} e(k)+k_{d} \Delta^{2} e(k)$, we have

$$
\begin{gathered}
\frac{\partial E}{\partial y_{\text {out }}}=e \\
\frac{\partial u}{\partial k_{p}}=\Delta e(k)=e(k)-e(k-1), \\
\frac{\partial u}{\partial k_{i}}=e(k), \\
\frac{\partial u}{\partial k_{d}}=\Delta^{2} e(k)=e(k)-2 e(k-1)+e(k-2) .
\end{gathered}
$$

Generally, Jacobian transformation $\partial y_{\text {out }} / \partial u$ is replaced by $\partial y_{m} / \partial u$ to simplify the calculation. $\partial y_{m} / \partial u$ is listed in

$$
\frac{\partial y_{m}}{\partial u}=\frac{\partial \sum_{i=1}^{4} w_{i} h_{i}}{\partial u}=\frac{\partial\left[w_{i} \sum_{i=1}^{4} h_{i}\right]}{\partial u}=\sum_{i=1}^{4} w_{i} h_{i} \frac{x_{1}-C_{i 1}}{2 b_{i}^{2}}
$$

3.3. Inner Loop for Pressure Regulation. Modeling proportional pressure regulator is complicated and usually consists of a chamber continuity equation, an orifice flow equation, and a force balance equation of the spool, all of which are listed as follows:

$$
\begin{gathered}
G=\frac{V_{c}}{\gamma R T} \frac{d p}{d t} \\
G=c_{q} A_{q} p_{s} \sqrt{\frac{2}{R T}} \varphi\left(\frac{p}{p_{s}}\right) \\
m \ddot{x}=k U_{e}-A_{f} p-k_{s}\left(x_{v}+x_{0}\right)-b \dot{x}_{v}-F_{c} \operatorname{sgn}\left(\dot{x}_{v}\right),
\end{gathered}
$$

where $\gamma$ is the ratio of specific heat and $\gamma=1.4$ for air, $R$ is the universal gas constant and $R=287 \mathrm{~J} / \mathrm{kgK}, V_{c}$ is the volume of the sealed chamber, $c_{q}$ is the flow coefficient, $A_{q}$ is the effective opening area of the orifice that changes with spool position, $p$ and $p_{s}$ are the upstream and downstream pressure, respectively, $m$ is the mass of the spool, $x_{0}$ is the initial position and $x_{v}$ is current displacement of the spool, and $A_{f}$ is the effective cross-sectional area of the bottom of spool. The detailed process is in [39].

The pressure dynamics within PMA is obtained with the assumption that both charging and discharging process are in isothermal and adiabatic states. Based on the polytropic gas law, the relationship among air mass $m$, muscle volume $V$, and the inertial pressure $p$ is expressed as follows:

$$
p\left[\frac{V}{m}\right]^{r}=\text { const. }
$$

Performing differential action of above equation and combining the law $p V=m R T$ for ideal gas, one can get the building up pressure process inside PMA

$$
\dot{p}=\frac{\gamma}{V}(\dot{m} R T-P \dot{V}) .
$$

The muscle volume varies along with contracting position and its accurate value is difficult to acquire. Assuming the shape of PMA to be cylindrical in order to simplify the complex problem, approximate volume is calculated as follows:

$$
V=\frac{\pi D^{2}}{4} L=\frac{b_{0}^{2}-L^{2}}{4 \pi n^{2}} L,
$$

where $L$ is the length of PMA in contractile process, $b_{0}$ the length of single fiber thread surrounding around bladder, and $n$ the number of times a thread encircles the PMA circumference from one end cap to the another end cap.

From above dynamic models, we find that the pressure building up process depends not only on nonlinear flow function, but also on muscle volume variation and air temperature. In order to regulate the pressure within PMA, these high nonlinear dependencies should be handled properly. However, geometric parameters of regulator and PMA are difficult to measure. In this paper, nonparametric RBFNN-PID controller is adopted to handle the high nonlinear pressure building up process. The schematic is shown in Figure 7. The inputs of the RBFNN for inner loop are $\left[v(k), P_{\text {out }}(k), P_{\text {out }}(k-1)\right]^{T}$, where $v(k)$ is the input voltage of the regulator and $P_{\text {out }}$ is the sampled pressure value within PMA.

3.4. Outer Loop for Position Control. To realize accurately position tracking, PMA model (2) and manipulator dynamics (16) are incorporated to devise the outer loop for position control. The scheme is shown in Figure 8. The outer loop also uses RBFNN tuned PID algorithm to handle model uncertainties and high nonlinear properties inside PMA and the manipulator. The output of the outer loop is the desired torque $\tau_{\text {ref }}$ for manipulator, which is used to calculate the desired pressure for inner loop control. The desired velocity and acceleration of PMA are obtained from first-order differential and second-order differential of desired position and then used in calculating desired pressure. The PID parameters $k_{p}, k_{i}$, and $k_{d}$ are updated using RBFNN algorithm. The input vector of RBFNN for outer loop is $\left[\tau_{\text {ref }}(k), X_{\text {out }}(k), X_{\text {out }}(k-\right.$ $1)]^{T}$. 


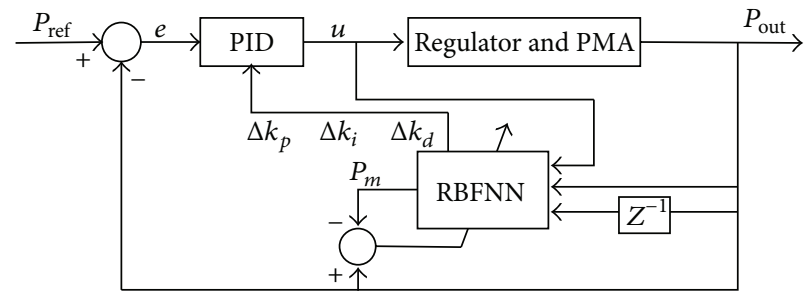

FIGURE 7: Schematic of inner pressure loop controlling algorithm.

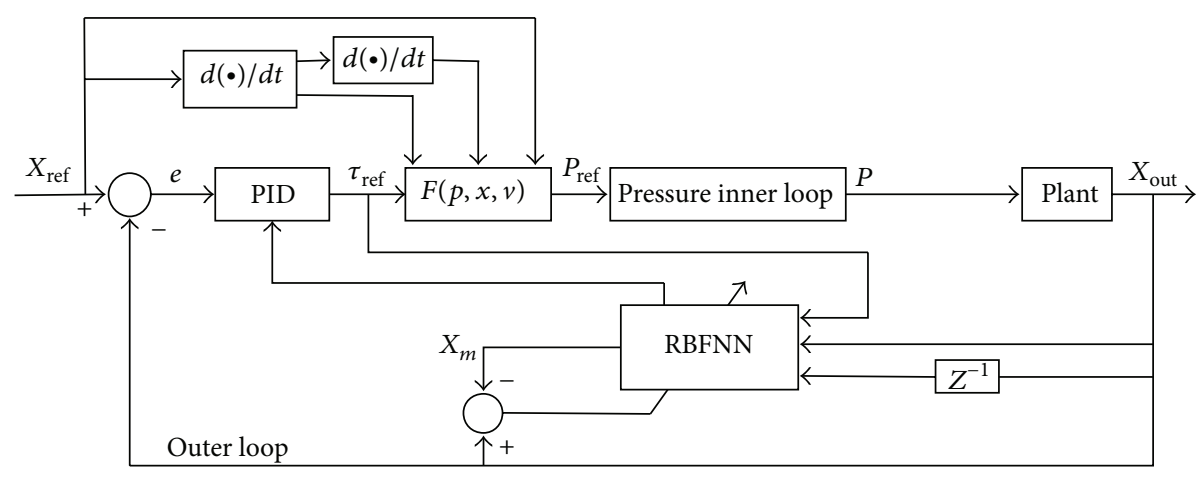

FIgURE 8: The scheme of the cascade position control of the SDOF system.

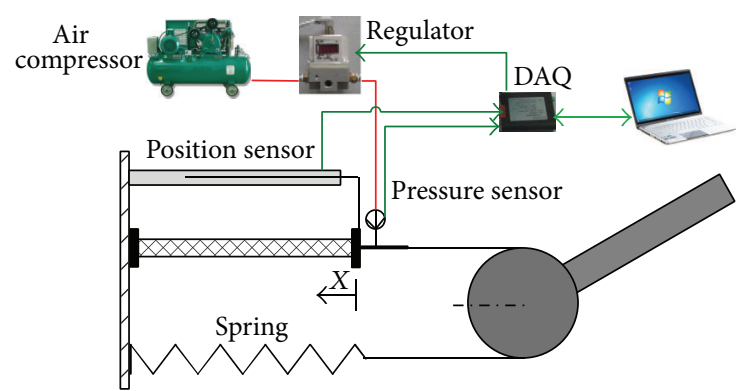

(a)

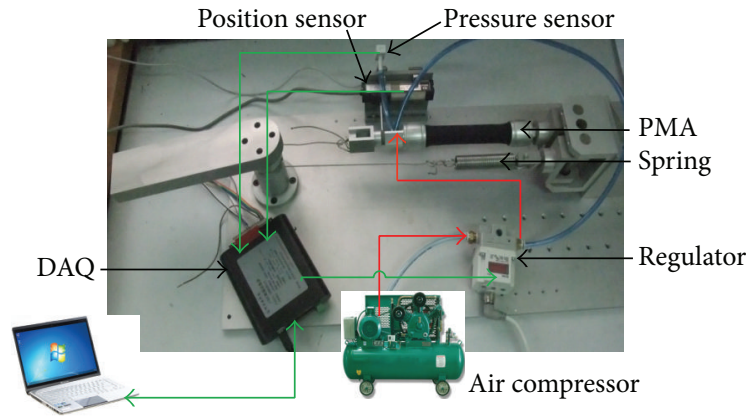

(b)

FIgURE 9: 1-DOF setup actuated by PMA. (a) Schematic diagram; (b) photograph.

\section{Experimental Validation}

4.1. 1-DOF Manipulator Actuated by PMA. The manipulator designed in our lab is shown in Figure 9. This 1-DOF setup is driven by a PMA and its reset motion to equilibrium position is realized by the spring's restoring force. This manipulator works in a horizontal plane. PMA (DMSP-20-120RMCM, FESTO Corporation) with a maximum contractile ratio of $25 \%$ at $0.6 \mathrm{MPa}$ pressure is used in this setup. The initial parameters of this PMA are inner diameter of $20 \mathrm{~mm}$ and length of $120 \mathrm{~mm}$. The charging/discharging process for PMA is controlled by a proportional regulator (ITV1050-212N, SMC corporation). Displacement of PMA is sampled by a displacement sensor. Gauge pressure sensor (type of PSE510$\mathrm{R} 06, \mathrm{SMC}$ ) is to sample real-time pressure inside PMA. Data acquisition card (DAQ) is used to communicate with host computer and send command to proportional regulator. Obviously, the only controllable variable is the command voltage to pressure regulator. Load dynamics is built up as follows:

$$
\tau=\left(f-f_{\text {spring }}\right) r=J \ddot{\theta},
$$

where $\tau[\mathrm{N} \cdot \mathrm{cm}]$ is the resultant torque, $J$ is moment of inertia, and $f[\mathrm{~N}]$ and $f_{\text {spring }}[\mathrm{N}]$ are PMA force and spring force, respectively. $r[\mathrm{~m}]$ is the radius of rotary base and $\theta$ [rad] is the angular displacement.

4.2. Validation of RBFNN PID Algorithm for Pressure Loop. Figure 10 shows the response of convention PID controller under the input command of square wave with frequency $0.1 \mathrm{~Hz}$ and magnitude 0.5 MPa. Obviously, square wave command essentially provides step inputs in both directions repeatedly. Response of RBFNN PID controller under the identical input command is also plotted in Figure 10. Comparison between the two response curves demonstrates that 


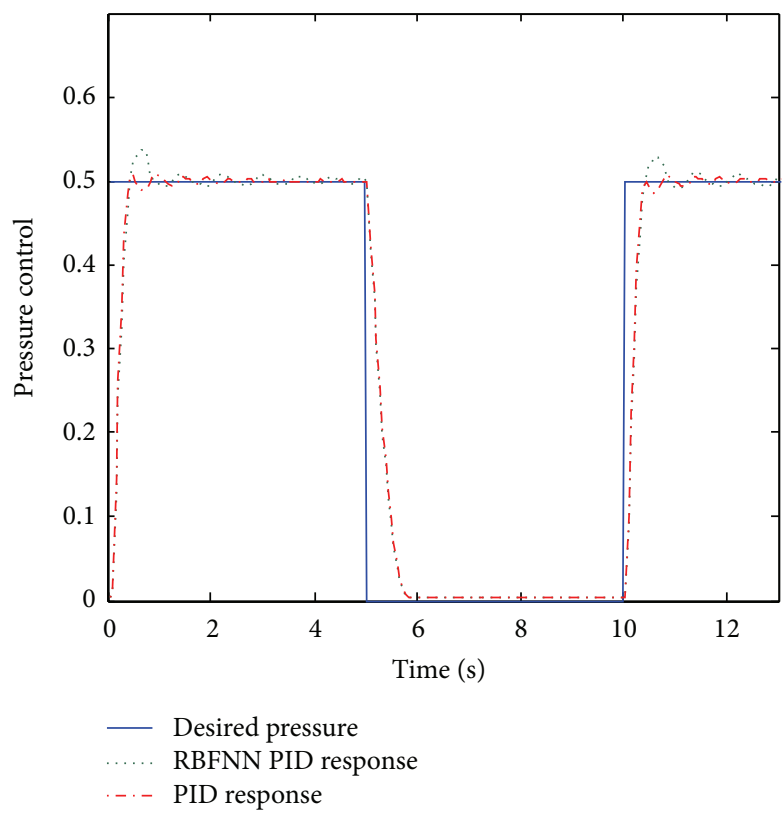

FIGURE 10: Response of RBFNN PID controller and that of classic PID controller for pressure loop.

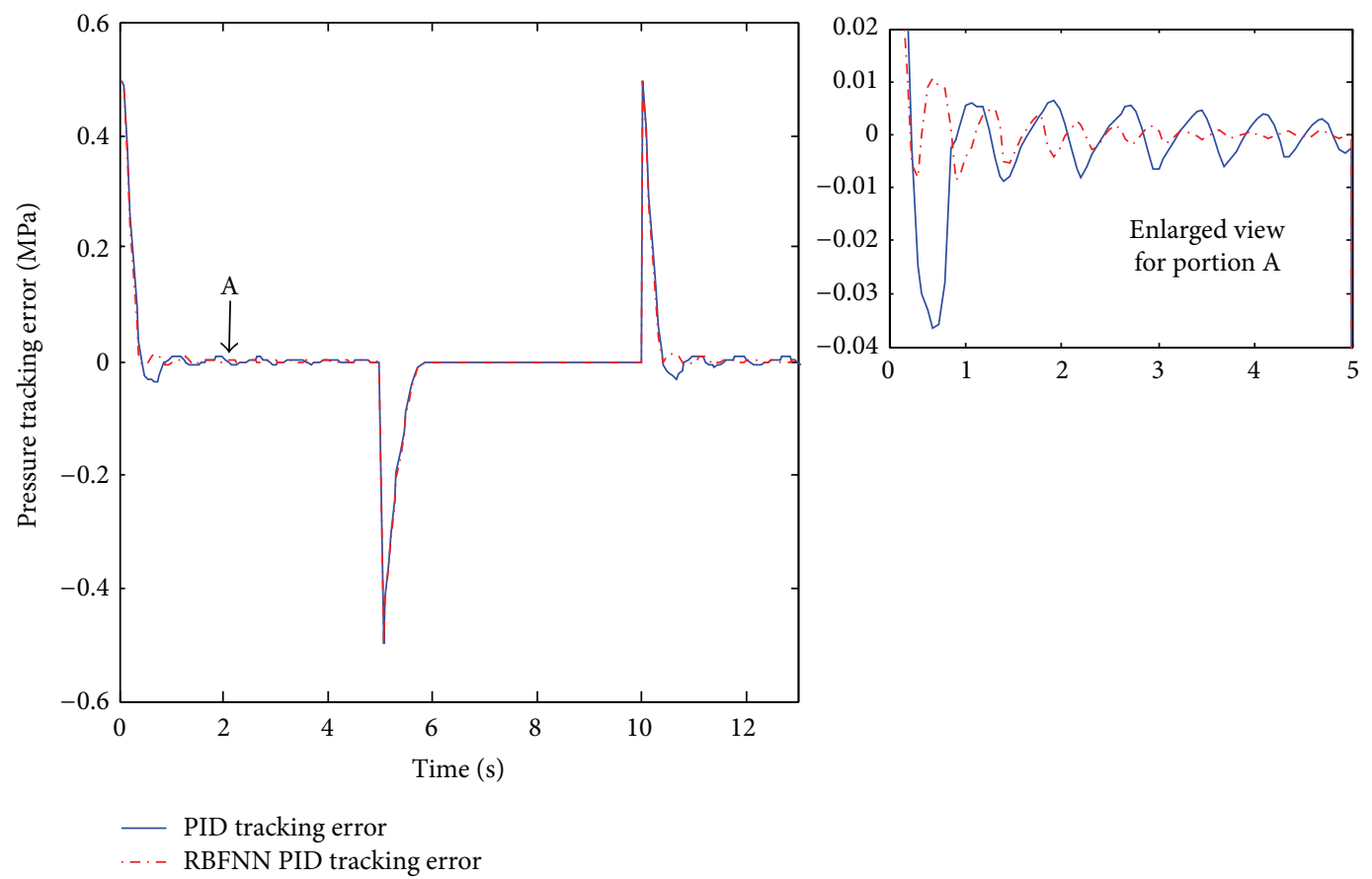

FIGURE 11: Pressure tracking error of classic PID controller and RBFNN PID controller.

response of RBFNN PID controller performs better than response of classic PID controller. The maximum overshoot of $8 \%$ occurs in the response of classic PID controller, while the transient response curve of RBFNN PID controller has a maximum overshoot of $1 \%$. It is observed that oscillation in response of classic PID controller is larger and stronger than that of RBFNN PID controller, although the rising times are almost identical. Figure 11 shows the corresponding tracking error curves. From the enlarged view on the top right of
Figure 11, we find that steady state error of RBFNNPID is much smaller than that of classic PID controller at highest equilibrium position. The tracking error of response from RBFNN PID controller is in the interval [-0.01, 0.01] ( $\mathrm{MPa})$, which means the ratio ranges from $-2 \%$ to $2 \%$. This tracking error domain shows a very high accuracy achieved by the RBFNN PID algorithm. Figure 12 shows the varying process of parameters $k_{p}, k_{i}$, and $k_{d}$ for RBFNN PID controller. The initial values of $k_{p}, k_{i}$, and $k_{d}$ in RBFNN PID controller 


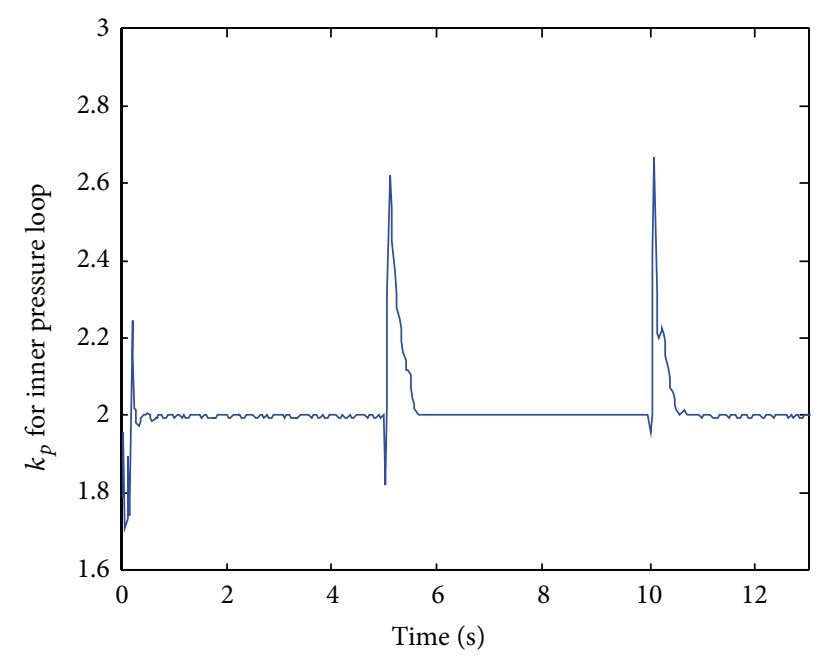

(a)

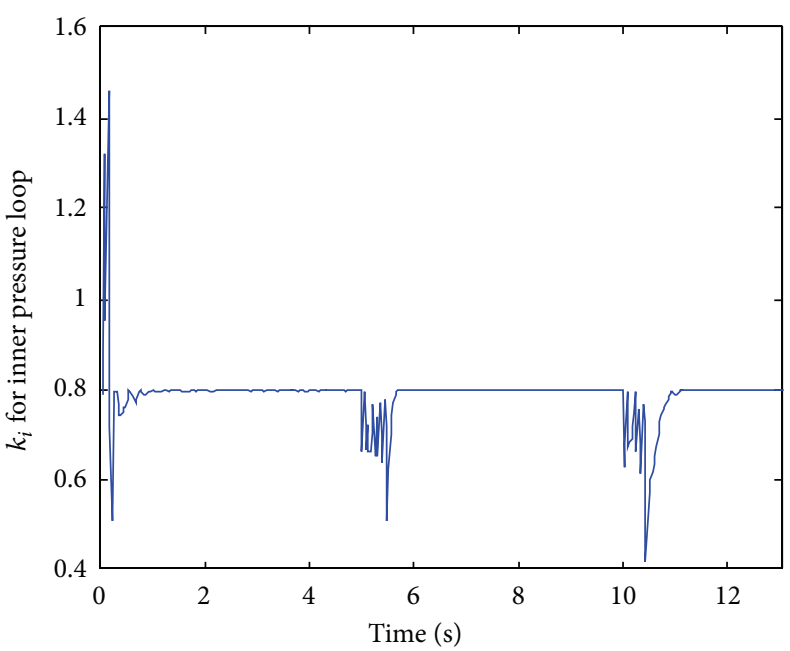

(b)

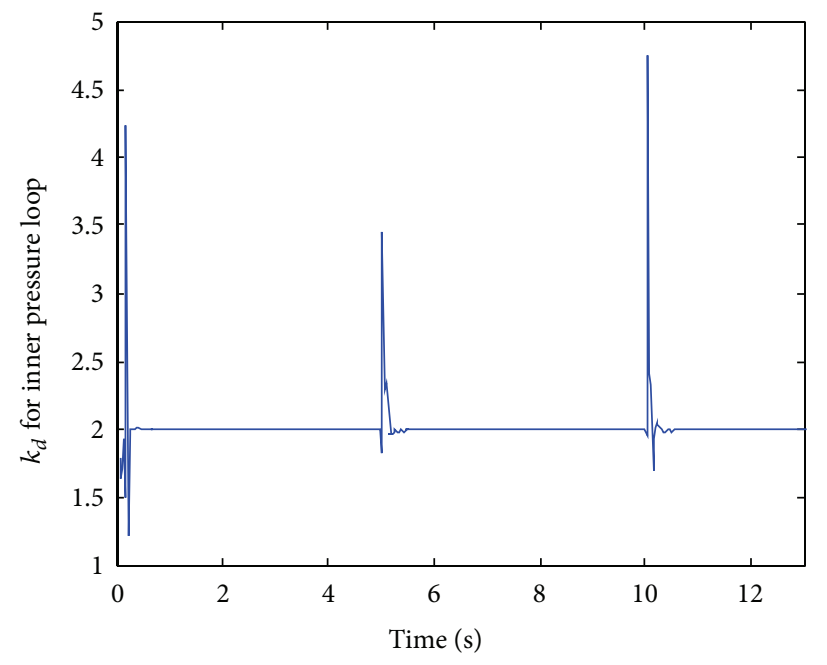

(c)

FIGURE 12: Variance of parameters of RBFNN PID controller $k_{p}, k_{i}, k_{d}$ under square excitation of $0.1 \mathrm{~Hz}$ and amplitude of $0.5 \mathrm{MPa}$.

are equal to the corresponding values of conventional PID controller, which are tuned by trials and errors. Obviously, parameters $k_{p}, k_{i}$, and $k_{d}$ vary around their initial values, respectively.

4.3. Validation of RBFNN PID Algorithm for Position Loop. Experiments are performed to validate the proposed cascade controller. In this paper, square wave and sinusoidal wave excitations are applied to the manipulator. To show the capacity of RBFNN PID algorithm, classic PID algorithm is also applied to the manipulator and response curves are plotted together. Note that the classic PID controller here means that outer position loop adopts classic PID algorithm, whilst the inner pressure loop uses RBFNN PID algorithm. RBFNN PID in this section refers to that both outer position loop and inner pressure loop adopt RBFNN PID algorithm.

Figure 13 shows the position response to square wave input of $0.1 \mathrm{~Hz}$ and amplitude $20 \mathrm{~mm}$. To perform the validation of the proposed controller, step response of classic PID cascade position controller is also plotted in Figure 13. Comparison between two response curves indicates that RBFNN PID response has less overshoot than classic PID response. The maximum overshoot of position response from classic PID controller is about $12.5 \%$, while the RBFNN PID experimental curves have maximum overshoot of $5 \%$ in $[0,2]$ (s) and about $4 \%$ in $[10,12](s)$. Reduction in maximum overshoot is because of adaptive tuning capacity on PID parameters. Enlarged view for A portion on the top right of Figure 13 shows details more clearly, from which the settling time for classic PID response and RBFNN PID response are $0.8(\mathrm{~s})$ and $1.5(\mathrm{~s})$, respectively. Enlarged view for B portion on the bottom right of Figure 13 shows response in descending stage in time interval $[4,7](\mathrm{s})$, from which we observe that response curve of RBFNN PID algorithm descends more rapidly than that of classic PID algorithm. The faster descending capacity is owed to the continuously PID parameter selftuning action. Steady state error of BPNNPID controller is 

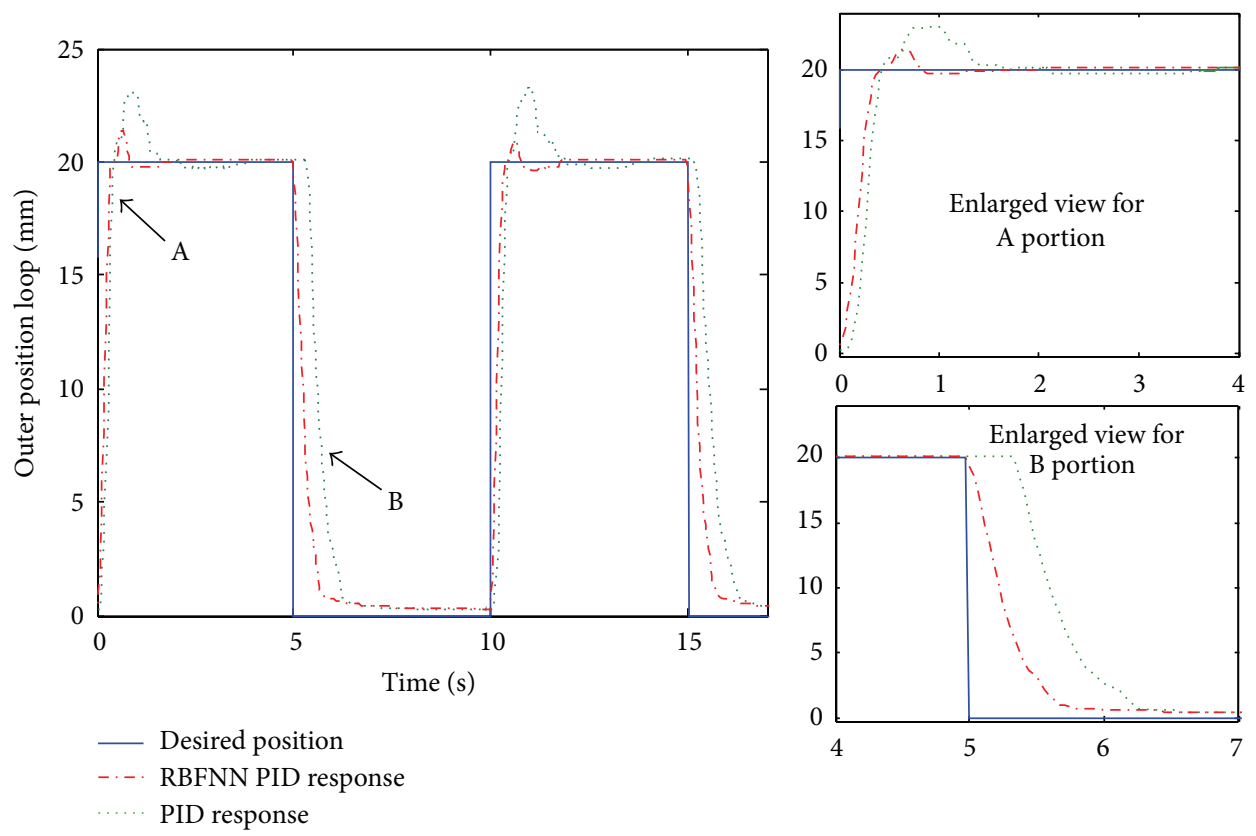

FIGURE 13: Comparison between responses of the RBFNN PID cascade position controller and that of classic PID cascade controller under a square wave of $0.1 \mathrm{~Hz}$ with amplitude $20 \mathrm{~mm}$.

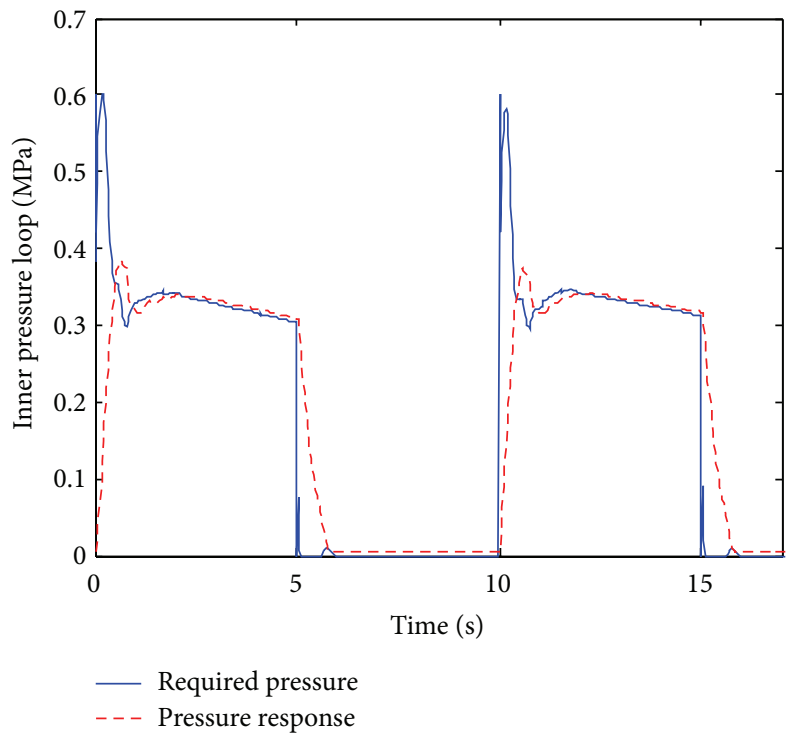

FIGURE 14: Inner desired pressure loop and responses of RBFNN PID pressure controller under square excitation of $0.1 \mathrm{~Hz}$ and amplitude of $20 \mathrm{~mm}$.

found to be smaller than that of classic PID algorithm. The global performance of RBFNN PID algorithm is better than that of classic PID algorithm, not only in reduction of overshoot and oscillation, but also in steady state error. Figure 14 shows the desired pressure and response of inner pressure RBFNN PID loop. Figure 15 shows the varying process of PID parameters $k_{p}, k_{i}$, and $k_{d}$ along with tracking process. The values of $k_{p}, k_{i}$, and $k_{d}$ for outer classic PID algorithm are equal to $k_{p}(0), k_{i}(0)$, and $k_{d}(0)$ of outer RBFNN PID controller whilst $k_{p}, k_{i}$, and $k_{d}$ for inner pressure classic PID algorithm are equal to $k_{p}(0), k_{i}(0)$, and $k_{d}(0)$ of inner RBFNN
PID controller. From Figure 15 we find that parameters of RBFNN PID controller vary around their initial values, respectively.

Another experimental curve set is plotted in Figure 16. A square wave excitation with frequency $0.1 \mathrm{~Hz}$ and amplitude $15 \mathrm{~mm}$ is applied to the manipulator. Observing the response curve of classic PID algorithm, we find maximum overshoot at the rising stage $[0,2](\mathrm{s})$ and $[10,12](\mathrm{s})$ is about $20 \%$ and large oscillation occurs at the beginning of descending stage. Maximum overshoot in curves of RBFNN PID controller is obviously less than that of classic PID controller, and small 


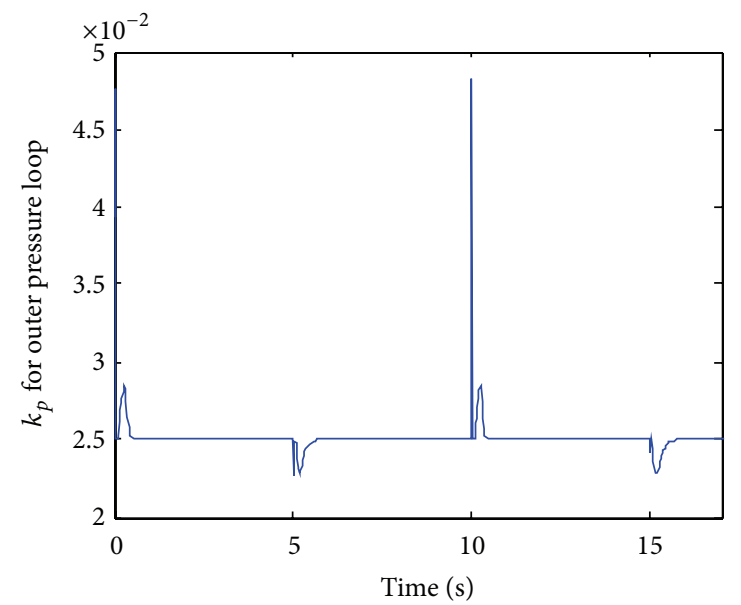

(a)

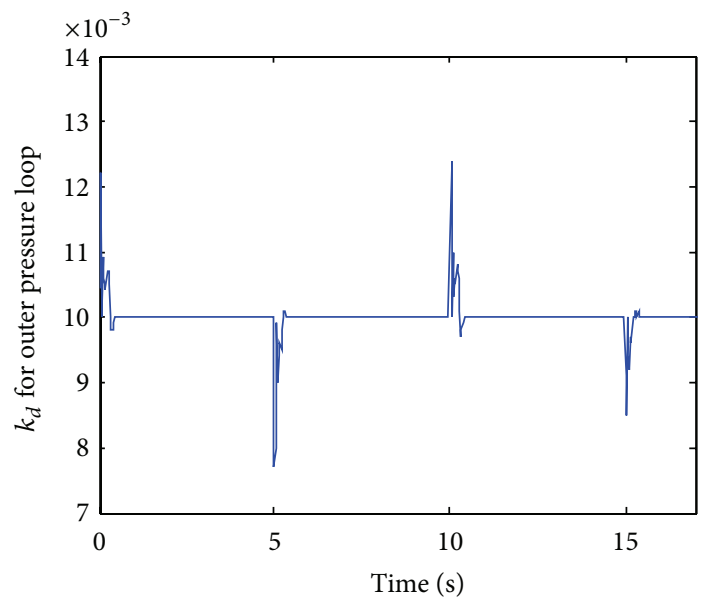

(c)

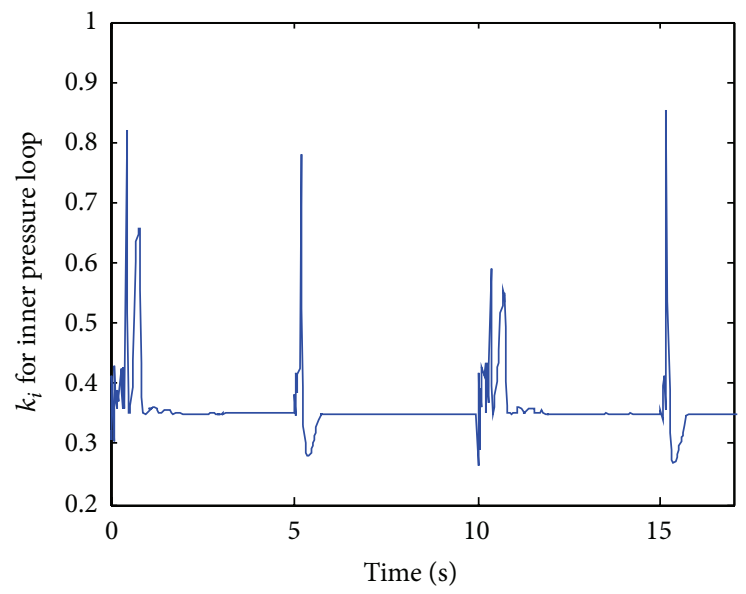

(e)

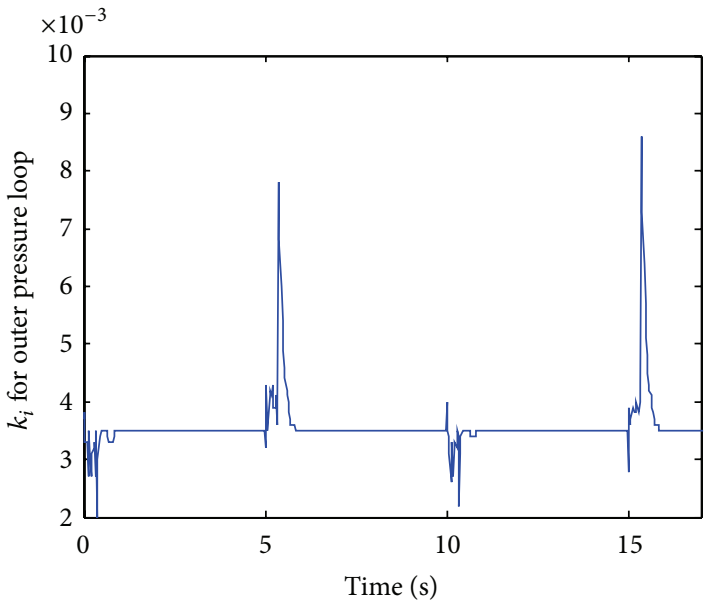

(b)

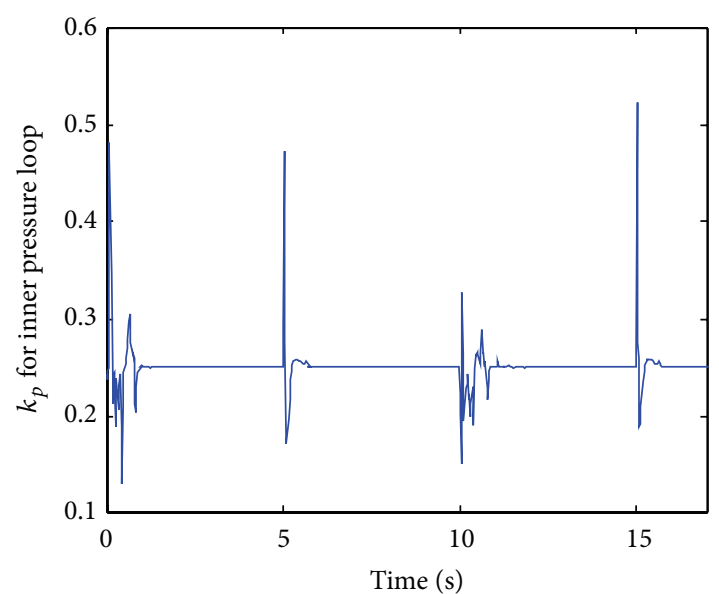

(d)

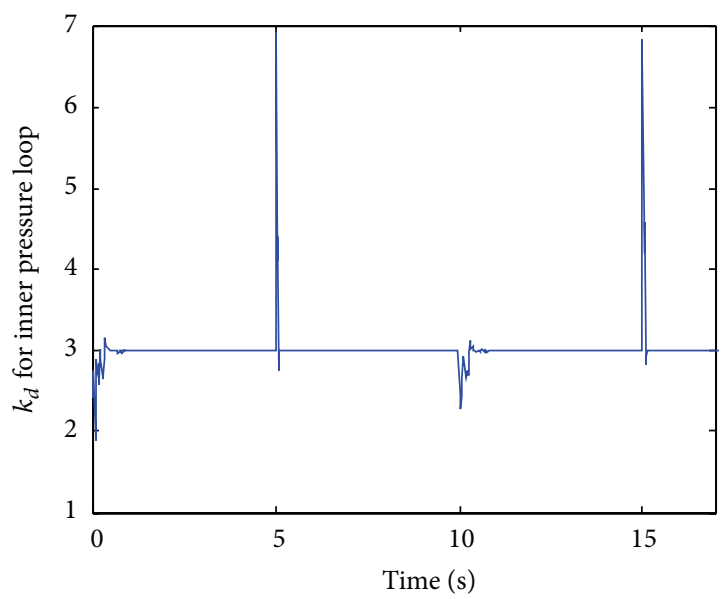

(f)

FIGURE 15: Variance of parameters of RBFNN PID controller $\left(k_{p}, k_{i}\right.$, and $\left.k_{d}\right)$ under square excitation of frequency $0.1 \mathrm{~Hz}$ and amplitude of $20 \mathrm{~mm}$. (a)-(c) Outer position RBFNN PID parameters $k_{p}, k_{i}$, and $k_{d}$, respectively; (d)-(f) inner pressure RBFNN PID parameters $k_{p}, k_{i}$, and $k_{d}$, respectively. 

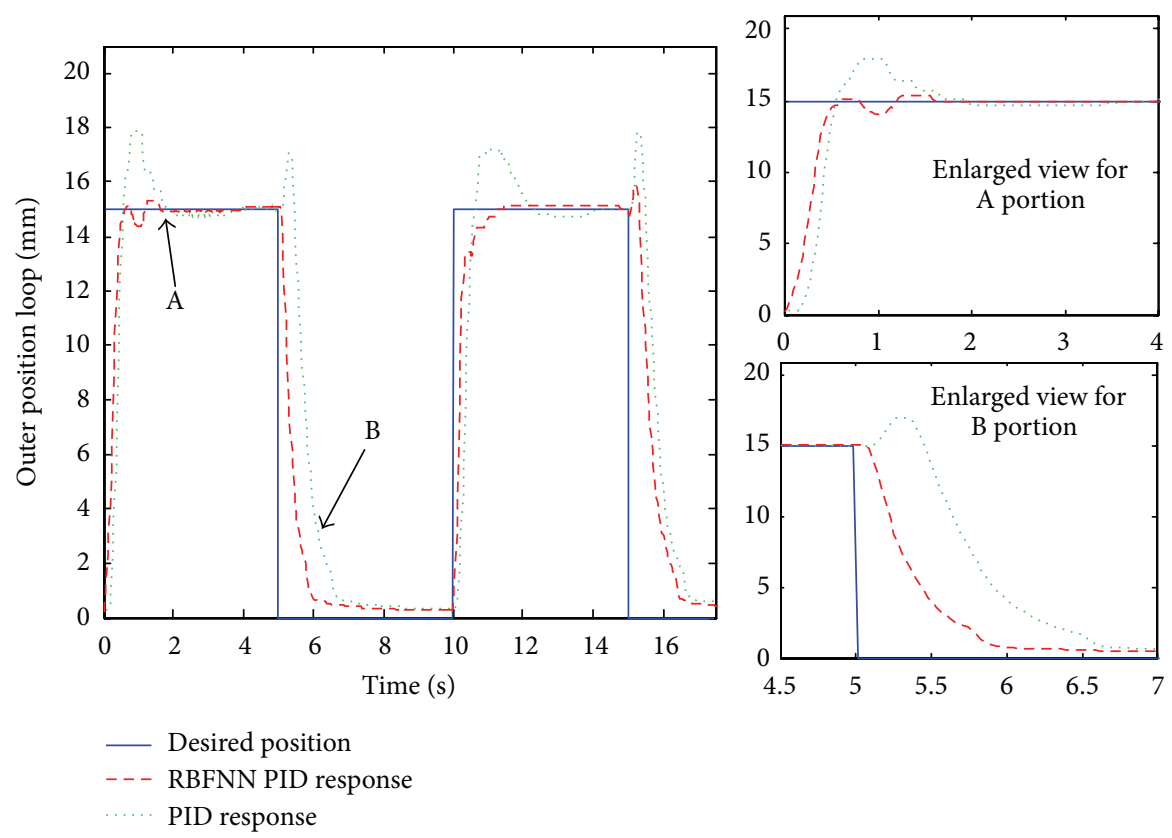

- RBFNN PID response
PID response

FIGURE 16: Comparison between responses of the RBFNN PID cascade position controller and that of classic PID cascade controller under a square wave of $0.1 \mathrm{~Hz}$ with amplitude $15 \mathrm{~mm}$.

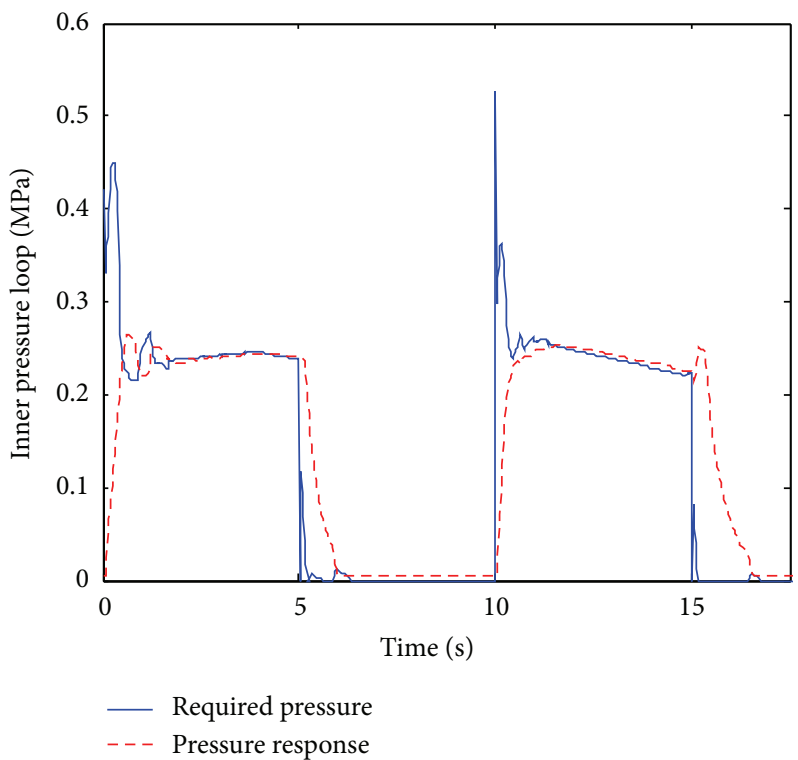

FIGURE 17: Inner desired pressure loop and responses of RBFNN PID pressure controller under square excitation of $0.1 \mathrm{~Hz}$ and amplitude of $15 \mathrm{~mm}$.

oscillation happens at the descending stages. RBFNN PID descends more rapidly than classic PID at the descending stages, which could be clearly observed in enlarged view of B portion on the bottom right of Figure 16. Inner desired pressure loop and its corresponding response of RBFNN PID loop under square excitation of $0.1 \mathrm{~Hz}$ and amplitude of $15 \mathrm{~mm}$ are shown in Figure 17. Variant process of PID parameters is plotted in Figure 18.

Sinusoid wave excitation of $0.1 \mathrm{~Hz}$ with amplitude $15 \mathrm{~mm}$ is applied to PMA and corresponding responses of RBFNN
PID controller and classic PID controller are plotted in Figure 19. From enlarged view for A portion on the top right of Figure 19 and enlarged view for B portion on the bottom right of Figure 19, we observe that response from RBFNN PID controller tracks the commanded position better than classic PID controller. Desired pressure for inner loop and its corresponding response of RBFNN PID pressure loop are plotted in Figure 20. The corresponding PID parameters for outer and inner control loop are shown in Figure 21. 


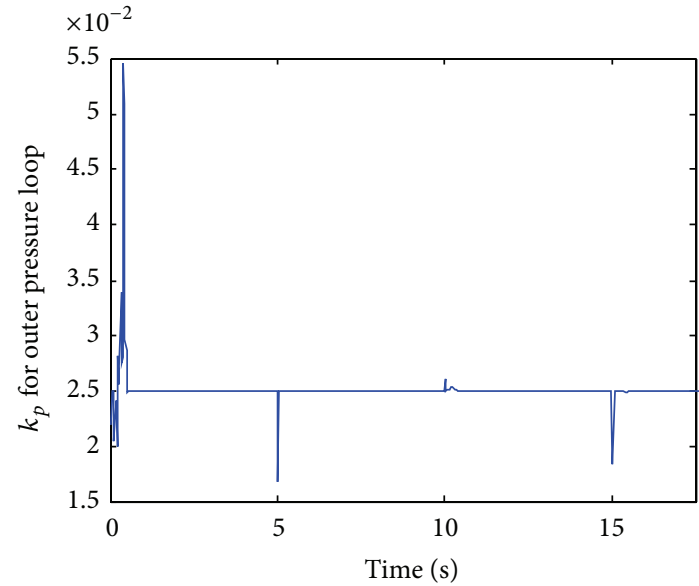

(a)

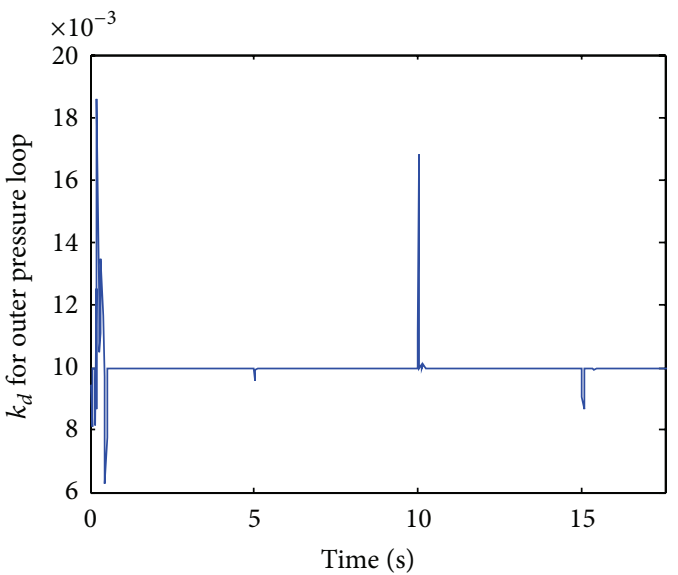

(c)

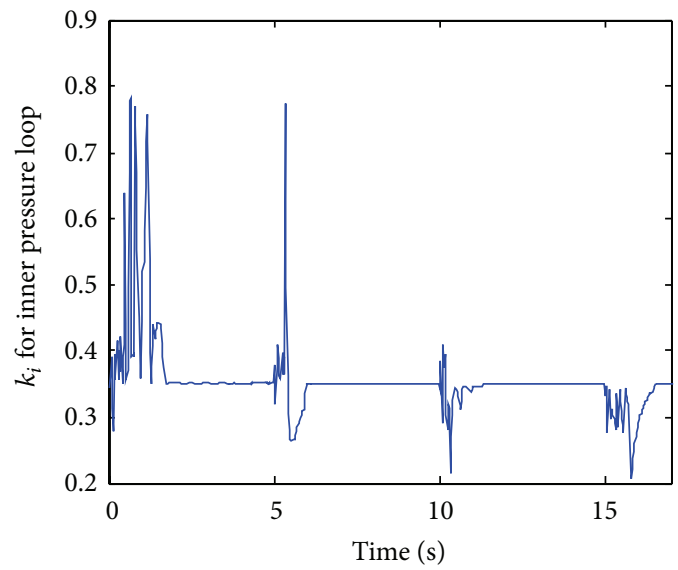

(e)

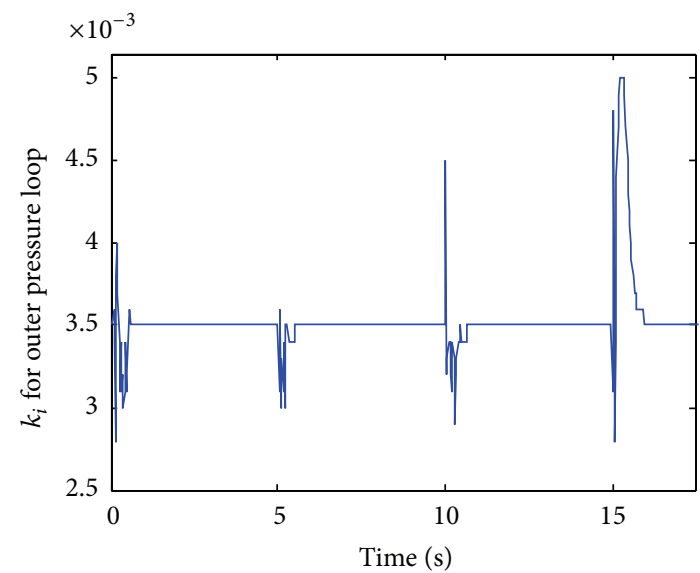

(b)

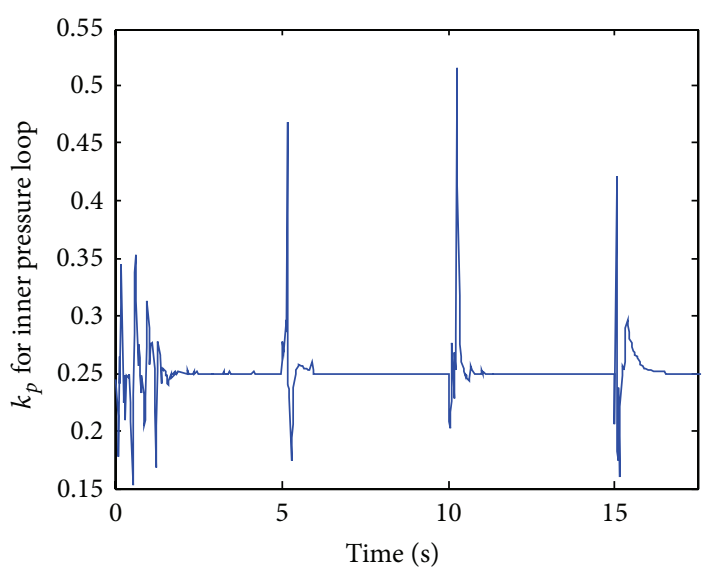

(d)

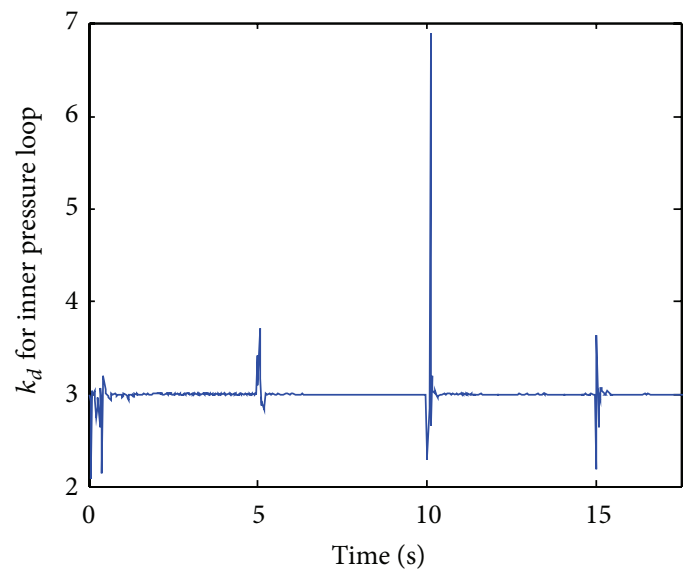

(f)

FIGURE 18: Variance of parameters of RBFNN PID controller $\left(k_{p}, k_{i}\right.$, and $\left.k_{d}\right)$ under square excitation of frequency $0.1 \mathrm{~Hz}$ and amplitude of $15 \mathrm{~mm}$. (a)-(c) Outer position RBFNN PID parameters $k_{p}, k_{i}$, and $k_{d}$, respectively; (d)-(f) inner pressure RBFNN PID parameters $k_{p}, k_{i}$, and $k_{d}$, respectively. 

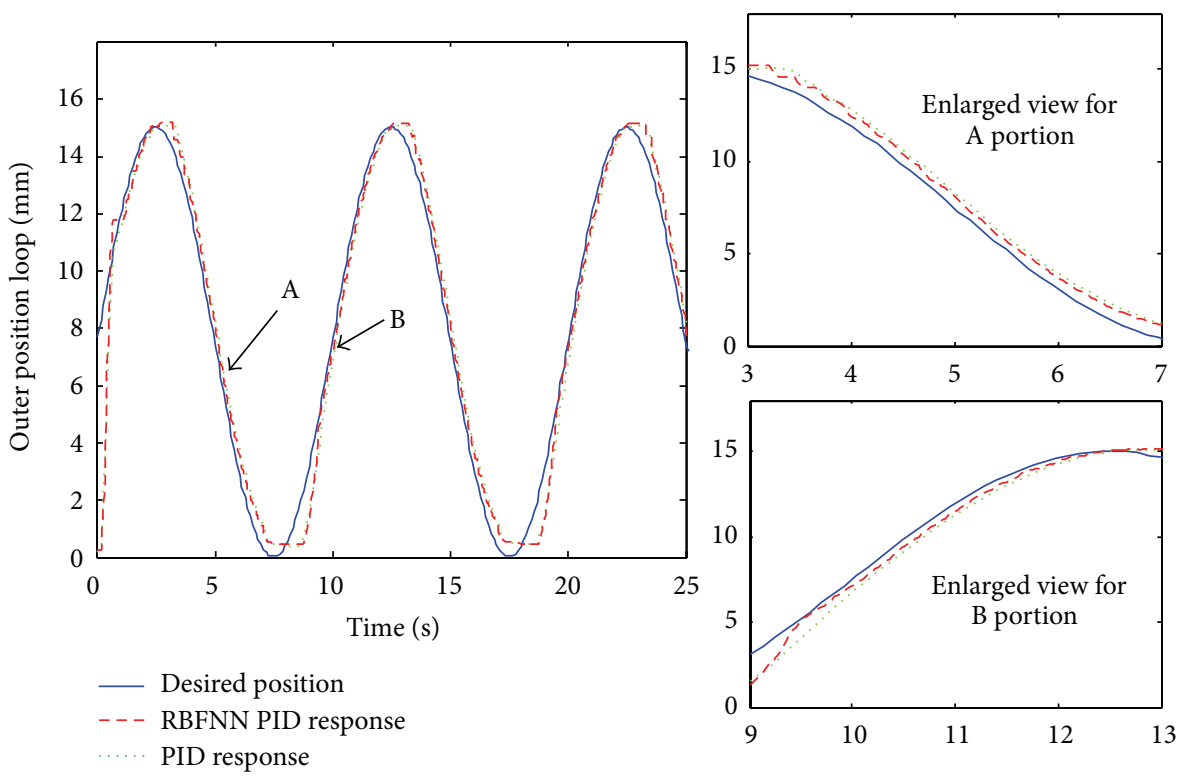

FIGURE 19: Comparison between response of the proposed cascade position controller and that of conventional cascade controller under sinusoid waves of $0.1 \mathrm{~Hz}$ with amplitude $15 \mathrm{~mm}$.

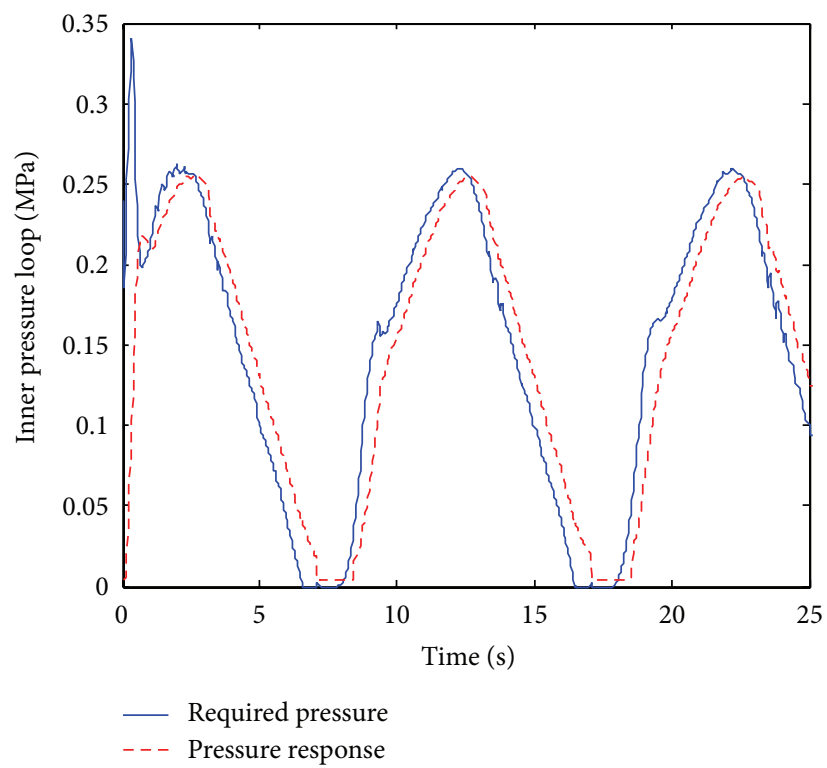

Figure 20: Inner desired pressure loop and responses of inner pressure loop under sinusoid excitation of $0.1 \mathrm{~Hz}$ and amplitude of $15 \mathrm{~mm}$.

\section{Conclusion}

The paper focuses on the accurate position tracking problem of PMA. To depict the nonlinear behavior of PMA, a phenomenological model is developed. By dividing the contractile force into linear and hysteretic component, corresponding parameters are identified on the basis of experimental data. Based on the phenomenological model, cascade position PID controller is proposed for a 1-DOF setup. The outer loop of the controller is to manipulate the position tracking problem, and the inner loop manipulates pressure dynamics within PMA. RBF Neural Network is introduced to the
PID algorithm. Model errors caused by high nonlinearities inside PMA and external disturbances can be dealt with by automatically tuning controller parameters of outer loop. Pressure dynamics within PMA is a high nonlinear process and RBFNN tuned PID controller shows flexibility on its uncertain nonlinearities. Results show the effectiveness of the novel controller on the manipulator. Limitations of this method are that the updating algorithm of RBFNN is complicated and initial parameters of PID controller should be tuned by trials and errors. Further work is to develop more simple updating criteria by adopting other learning algorithms and develop bionic robots using PMA. 


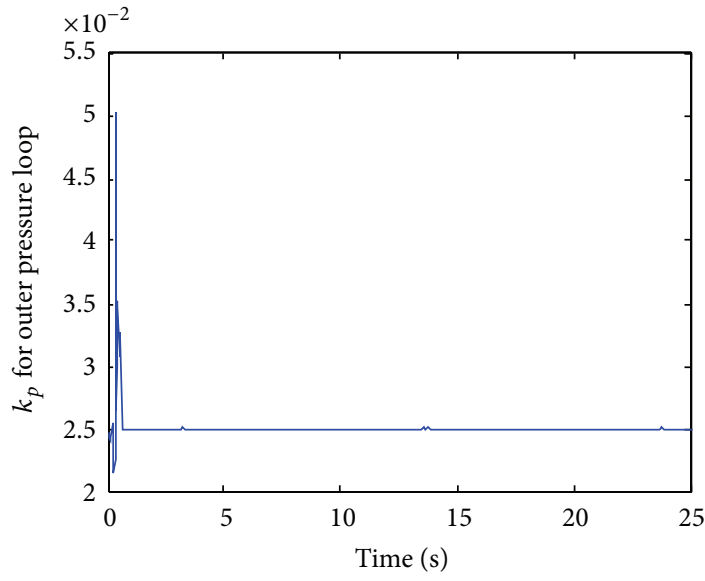

(a)

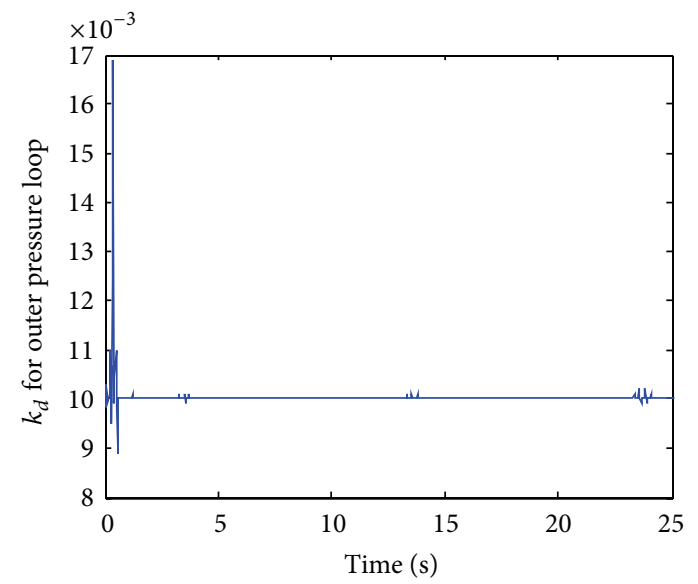

(c)

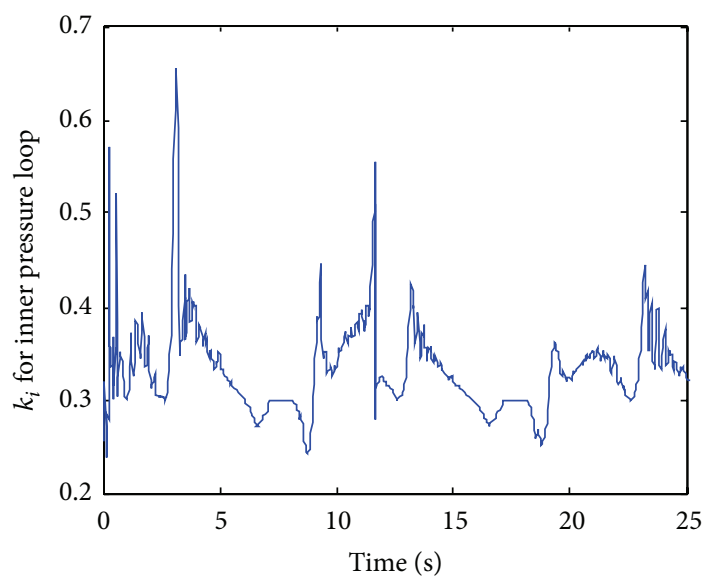

(e)

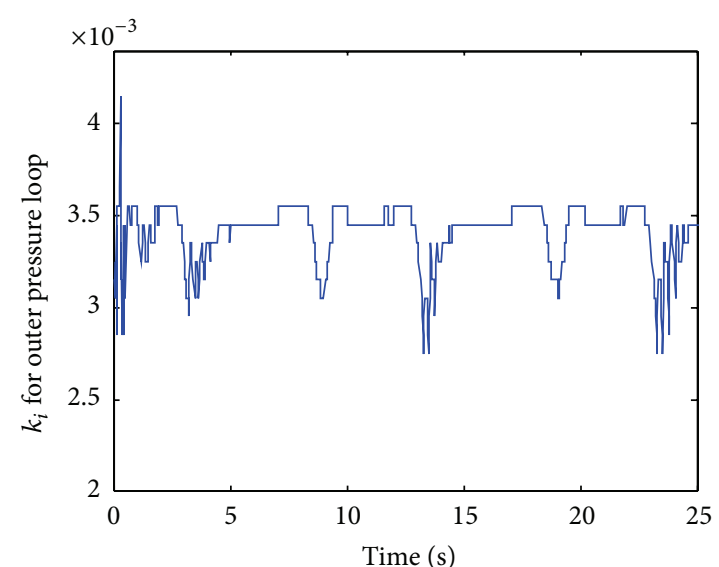

(b)

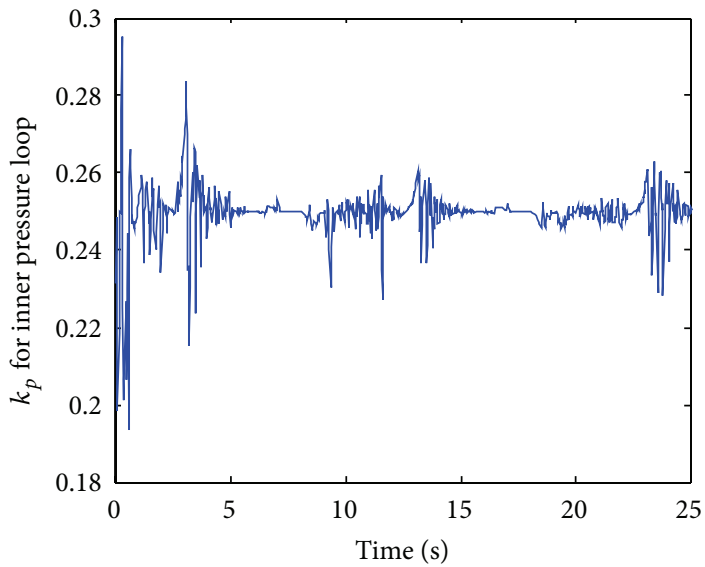

(d)

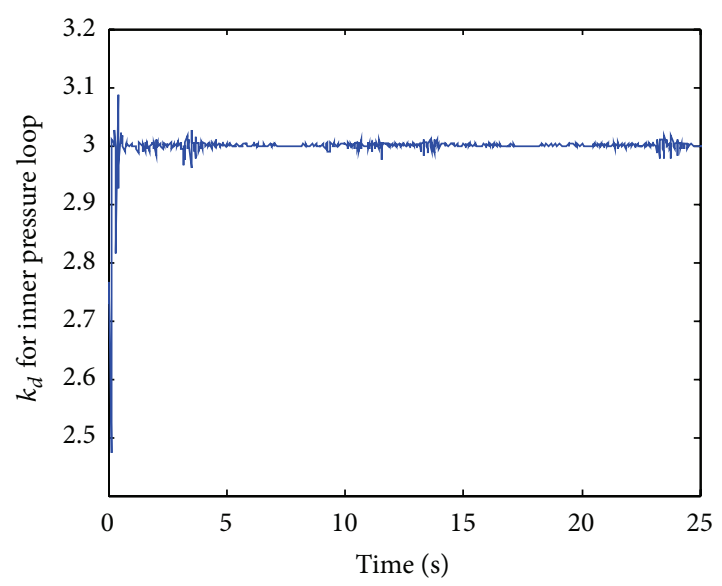

(f)

FIGURE 21: Variance of parameters of proposed PID controller $\left(k_{p}, k_{i}\right.$, and $\left.k_{d}\right)$ under sinusoid excitation of frequency $0.1 \mathrm{~Hz}$ and amplitude of $15 \mathrm{~mm}$. (a)-(c) Outer position RBFNN PID parameters $k_{p}, k_{i}$, and $k_{d}$, respectively; (d)-(f) inner pressure RBFNN PID parameters $k_{p}, k_{i}$, and $k_{d}$, respectively. 


\section{Conflict of Interests}

The authors declare that there is no conflict of interests regarding the publication of this paper.

\section{Acknowledgments}

This work was supported by National Natural Science Foundation of China (51005052); the Ministry of Education Doctoral Education Foundation (200 802131005); Harbin Institute of Technology Research and Innovation Fund (HIT.NSRIF.2009016); State Key Laboratory of Independent Topics (SKLRS201001C).

\section{References}

[1] L. Kopecny, "Producing of tactile feedback via pneumatic muscles," in Proceedings of the IEEE International Conference on Industrial Technology (ICIT '03), pp. 685-687, Maribor, Slovenia, December 2003.

[2] E. V. Mangan, D. A. Kingsley, R. D. Quinn, and H. J. Chiel, "Development of a peristaltic endoscope," in Proceedings of the IEEE International Conference on Robotics and Automation (ICRA '02), vol. 1, pp. 347-352, Washington, DC, USA, May 2002.

[3] E. V. Mangan, D. A. Kingsley, R. D. Quinn, G. P. Sutton, J. M. Mansour, and H. J. Chiel, "A biologically inspired gripping device," Industrial Robot, vol. 32, no. 1, pp. 49-54, 2005.

[4] T. Takuma, S. Nakajima, K. Hosoda, and M. Asada, "Design of self-contained biped walker with pneumatic actuators," in Proceedings of the SICE Annual Conference, vol. 3, pp. 2520-2524, Sapporo, Japan, August 2004.

[5] R. Vaidyanathan, H. J. Chiel, and R. D. Quinn, "Hydrostatic robot for marine applications," Robotics and Autonomous Systems, vol. 30, no. 1, pp. 103-113, 2000.

[6] R. T. Pack, J. L. Christopher Jr., and K. Kawamura, "A rubbertuator-based structure-climbing inspection robot," in Proceedings of the IEEE International Conference on Robotics and Automation, vol. 3, pp. 1869-1874, Albuquerque, NM, USA, April 1997.

[7] R. W. Colbrunn, Design and control of a robotic leg with braided pneumatic actuators [Master thesis], Department of Mechanical and Aerospace Engineering, Case Western University, Cleveland, Ohio, USA, 2000.

[8] V. L. Nickel, J. Perry, and A. L. Garrett, "Development of useful function in the severely paralyzed hand," The Journal of Bone \& Joint Surgery-American Volume, vol. 45, no. 5, pp. 933-952, 1963.

[9] H. Schulte, "The characteristics of the McKibben artificial muscle," in The Application of External Power in Prosthetics and Orthotics, pp. 94-115, National Academies, Lake Arrowhead, Calif, USA, 1961.

[10] G. K. Klute, J. M. Czerniecki, and B. Hannaford, "McKibben artificial muscles: pneumatic actuators with biomechanical intelligence," in Proceedings of the IEEE/ASME International Conference on Advanced Intelligent Mechatronics, pp. 221-226, Atlanta, Ga, USA, September 1999.

[11] L. Kopecny, "Producing of tactile feedback via pneumatic muscles," in Proceedings of the IEEE International Conference on Industrial Technology (ICIT '03), vol. 2, pp. 685-687, Maribor, Slovenia, December 2003.
[12] E. V. Mangan, D. A. Kingsley, R. D. Quinn, and H. J. Chiel, "Development of a peristaltic endoscope," in Proceedings of the IEEE International Conference on Robotics and Automation, vol. 1, pp. 347-352, Washington, DC, USA, May 2002.

[13] C.-P. Chou and B. Hannaford, "Measurement and modeling of McKibben pneumatic artificial muscles," IEEE Transactions on Robotics and Automation, vol. 12, no. 1, pp. 90-102, 1996.

[14] T. Raparelli, F. Durante, and P. B. Zobel, "Numerical modelling and experimental validation of a pneumatic muscle actuator," Proceedings of the JFPS International Symposium on Fluid Power, vol. 1999, no. 4, pp. 673-678, 1999.

[15] S. Hirai, P. Cusin, H. Tanigawa, T. Masui, S. Konishi, and S. Kawamura, "Qualitative synthesis of deformable cylindrical actuators through constraint topology," in Proceedings of the IEEE/RSJ International Conference on Intelligent Robots and Systems (IROS '00), vol. 1, pp. 197-202, Takamatsu, Japan, October-November 2000.

[16] G. Klute, J. Czerniecki, and B. Hannaford, "McKibben artificial muscles: pneumatic actuators with biomechanical intelligence," in Proceedings of IEEE/ASME International Conference on Advanced Intelligent Mechatronics, pp. 221-226, Atlanta, Ga, USA, September 1999.

[17] D. W. Repperger, C. A. Phillips, D. C. Johnson, R. D. Harmon, and K. Johnson, "A study of pneumatic muscle technology for possible assistance in mobility," in Proceedings of the 19th Annual International Conference of the IEEE Engineering in Medicine and Biology Society (EMBS '97), pp. 1884-1887, Chicago, Ill, USA, November 1997.

[18] D. B. Reynolds, D. W. Repperger, C. A. Phillips, and G. Bandry, "Modeling the dynamic characteristics of pneumatic muscle," Annals of Biomedical Engineering, vol. 31, no. 3, pp. 310-317, 2003.

[19] H. F. Schulte, "The characteristics of the McKibben artificial muscle," in The Application of External Power in Prosthetics and Orthotics, vol. 874, pp. 94-115, National Academy of Sciences, National Research Council, 1961.

[20] T. Nakamura, N. Saga, and K. Yaegashi, "Development of a pneumatic artificial muscle based on biomechanical characteristics," in Proceedings of the IEEE International Conference on Industrial Technology (ICIT '03), pp. 729-734, Maribor, Slovenia, December 2003.

[21] N. Tsagarakis and D. G. Caldwell, "Improved modelling and assessment of pneumatic muscle actuators," in Proceedings of the IEEE International Conference on Robotics and Automation (ICRA '00), pp. 3641-3646, San Francisco, Calif, USA, April 2000.

[22] S. Davis, N. Tsagarakis, J. Canderle, and D. G. Caldwell, "Enhanced modelling and performance in braided pneumatic muscle actuators," International Journal of Robotics Research, vol. 22, no. 3-4, pp. 213-227, 2003.

[23] A. M. Bertetto and M. Ruggiu, "Characterization and modeling of air muscles," Mechanics Research Communications, vol. 31, no. 2, pp. 185-194, 2004.

[24] D. Trivedi, A. Lotfi, and C. D. Rahn, "Geometrically exact models for soft robotic manipulators," IEEE Transactions on Robotics, vol. 24, no. 4, pp. 773-780, 2008.

[25] B. Tondu and P. Lopez, "Modeling and control of McKibben artificial muscle robot actuators," IEEE Control Systems, vol. 20, no. 2, pp. 15-38, 2000.

[26] T. V. Minh, T. Tjahjowidodo, H. Ramon, and H. van Brussel, "Control of a pneumatic artificial muscle (PAM) with 
model-based hysteresis compensation," in Proceedings of the IEEE/ASME International Conference on Advanced Intelligent Mechatronics (AIM '09), pp. 1082-1087, Singapore, July 2009.

[27] K. C. Wickramatunge and T. Leephakpreeda, "Study on mechanical behaviors of pneumatic artificial muscle," International Journal of Engineering Science, vol. 48, no. 2, pp. 188-198, 2010.

[28] D. G. Caldwell, G. A. Medrano-Cerda, and M. Goodwin, "Control of pneumatic muscle actuators," IEEE Control Systems Magazine, vol. 15, no. 1, pp. 40-48, 1995.

[29] D. W. Repperger, C. A. Phillips, and M. Krier, "Controller design involving gain scheduling for a large scale pneumatic muscle actuator," in Proceedings of the IEEE International Conference on Control Applications, pp. 285-290, August 1999.

[30] S. W. Chan, J. H. Lilly, D. W. Repperger, and J. E. Berlin, "Fuzzy $\mathrm{PD}+\mathrm{I}$ learning control for a pneumatic muscle," in Proceedings of the IEEE International Conference on Fuzzy Systems, vol. 1, pp. 278-283, 2003.

[31] P. Carbonell, Z. P. Jiang, and D. W. Repperger, "Nonlinear control of a pneumatic muscle actuator: backstepping vs. slidingmode," in Proceedings of the IEEE International Conference on Control Applications (CCA '01), pp. 167-172, Mexico City, Mexico, September 2001.

[32] M. van Damme, B. Vanderborght, P. Beyl et al., "Sliding mode control of a 'soft' 2-DOF planar pneumatic manipulator," International Applied Mechanics, vol. 44, no. 10, pp. 1191-1199, 2008.

[33] H. Aschemann and D. Schindele, "Sliding-mode control of a high-speed linear axis driven by pneumatic muscle actuators," IEEE Transactions on Industrial Electronics, vol. 55, no. 11, pp. 3855-3864, 2008.

[34] L. Zhang, J. Xie, and D. Lu, "Adaptive robust control of onelink joint actuated by pneumatic artificial muscles," in Proceedings of the 1st International Conference on Bioinformatics and Biomedical Engineering (ICBBE '07), pp. 1185-1189, Wuhan, China, July 2007.

[35] D. Schindele and H. Aschemann, "Nonlinear model predictive control of a high-speed linear axis driven by pneumatic muscles," in Proceedings of the American Control Conference, pp. 3017-3022, Seattle, Wash, USA, June 2008.

[36] M. K. Chang and J. C. Wu, "Tracking control of a two DOF arm actuated by pneumatic muscle actuators using adaptive fuzzy sliding mode controller," in Proceedings of the CACS Automatic Control Conference, St. John's University, Tamsui, Taiwan, November 2006.

[37] L. Udawatta, P. Priyadarshana, and S. Witharana, "Control of pneumatic artificial muscle for bicep configuration using IBC," in Proceedings of the 3rd International Conference on Information and Automation for Sustainability (ICIAFS '07), pp. 35-39, Melbourne, Australia, December 2007.

[38] H. J. M. T. S. Adriaens, W. L. de Koning, and R. Banning, "Modeling piezoelectric actuators," IEEE/ASME Transactions on Mechatronics, vol. 5, no. 4, pp. 331-341, 2000.

[39] X.-S. Wang, Y.-H. Cheng, and G.-Z. Peng, "Modeling and selftuning pressure regulator design for pneumatic-pressure-load systems," Control Engineering Practice, vol. 15, no. 9, pp. 11611168, 2007. 


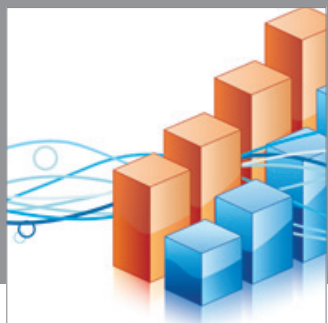

Advances in

Operations Research

mansans

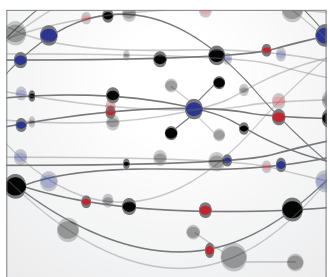

The Scientific World Journal
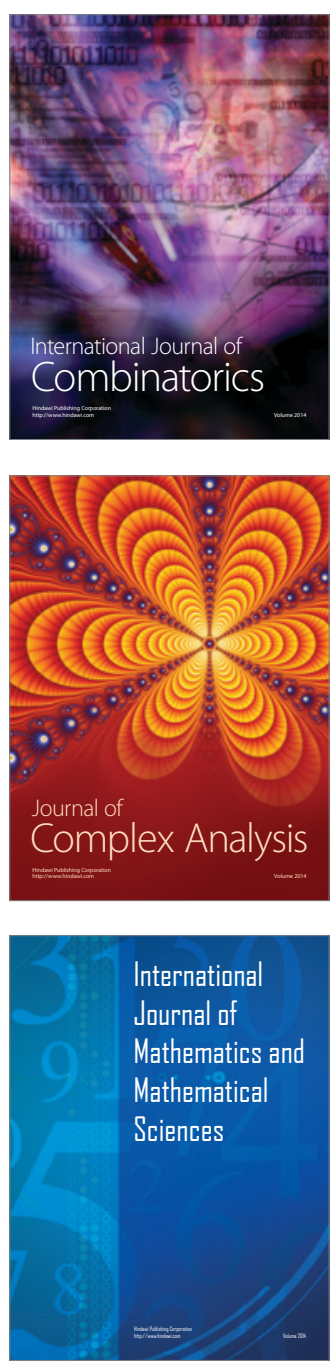
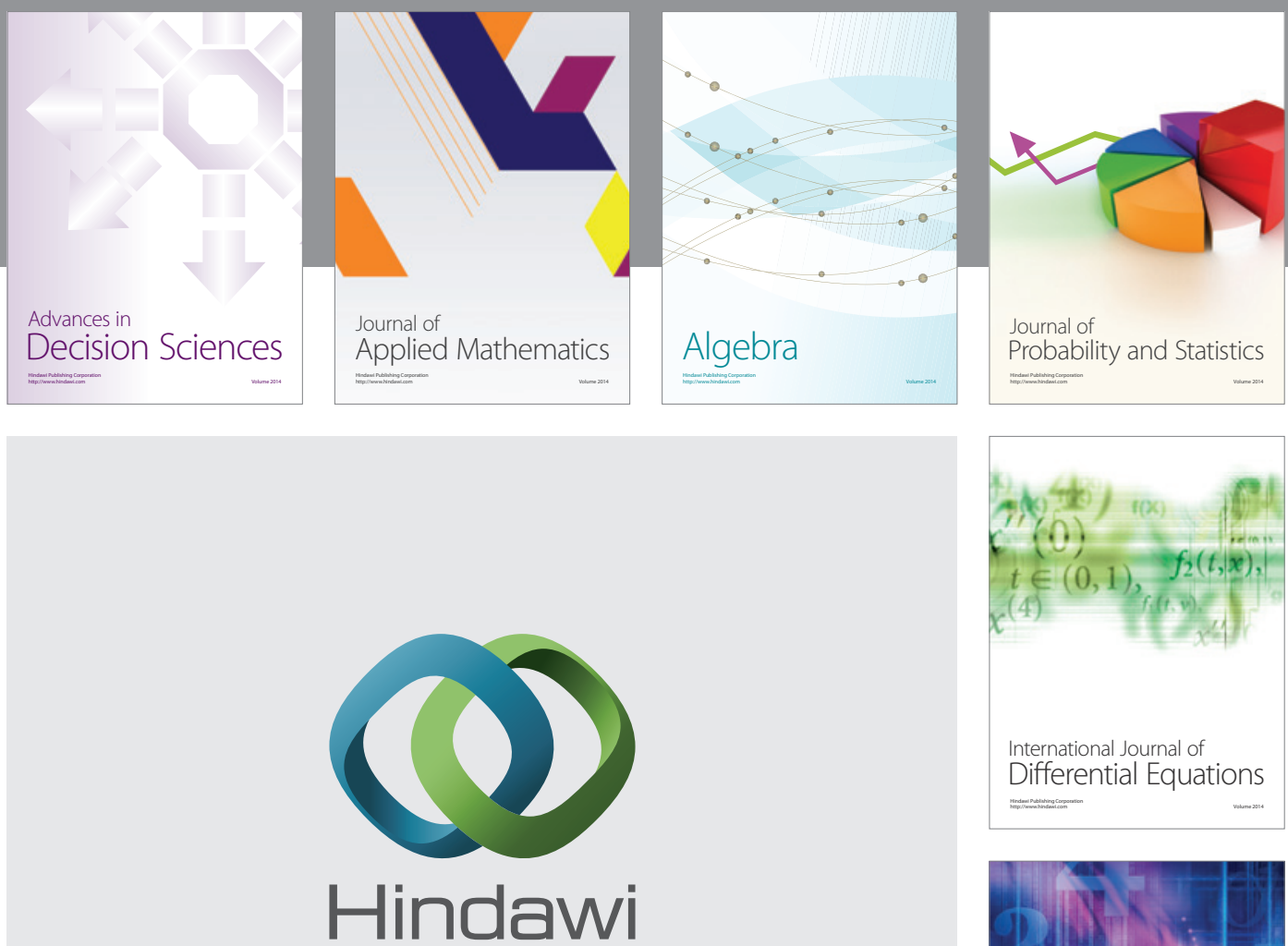

Submit your manuscripts at http://www.hindawi.com
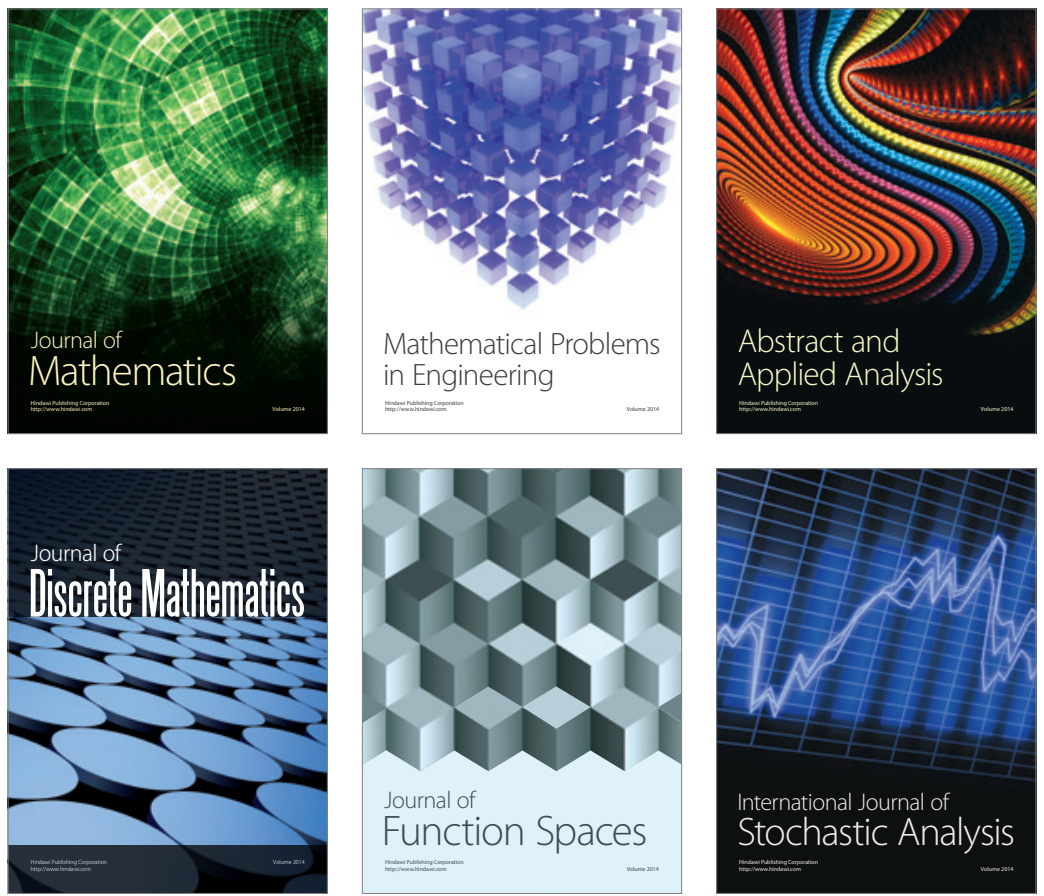

Journal of

Function Spaces

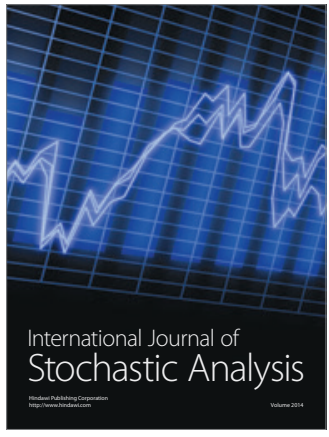

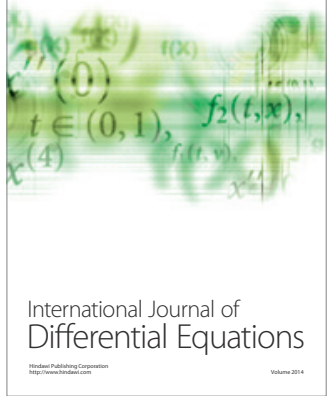
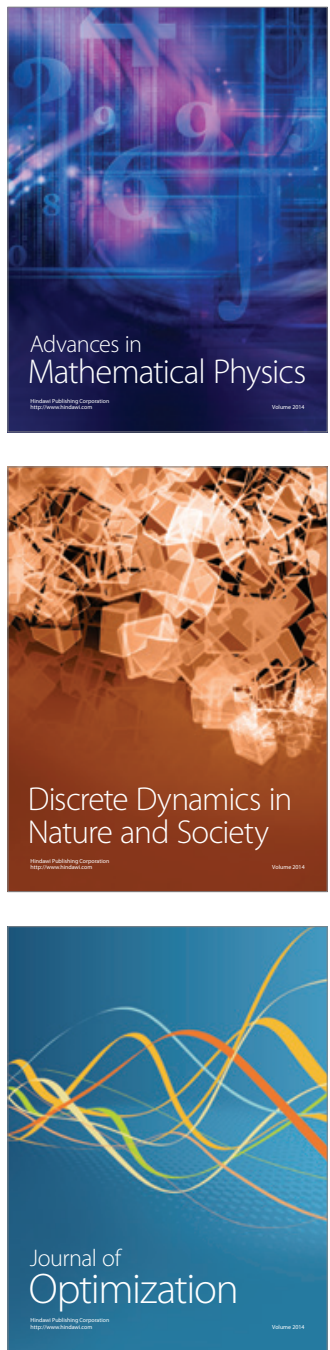